OPEN ACCESS

Edited by:

Benoit Viollet,

Institut National de la Santé et de la

Recherche Médicale (INSERM),

France

Reviewed by:

Arnim Pause,

McGill University, Canada

Vincent Giguère,

McGill University, Canada

*Correspondence:

Abitha Sukumaran

Abitha.sukumaran@cchmc.org

Biplab Dasgupta

biplab.dasgupta@cchmc.org

Specialty section:

This article was submitted to

Cellular Biochemistry,

a section of the journal

Frontiers in Cell and Developmental

Biology

Received: 25 March 2020

Accepted: 02 July 2020

Published: 29 July 2020

Citation:

Sukumaran A, Choi K and

Dasgupta $B(2020)$ Insight on

Transcriptional Regulation of the

Energy Sensing AMPK

and Biosynthetic mTOR Pathway

Genes. Front. Cell Dev. Biol. 8:671.

doi: $10.3389 /$ fcell.2020.00671

\section{Insight on Transcriptional Regulation of the Energy Sensing AMPK and Biosynthetic mTOR Pathway Genes}

\author{
Abitha Sukumaran ${ }^{1 *}$, Kwangmin Choi $^{2}$ and Biplab Dasgupta ${ }^{1 *}$ \\ ' Division of Oncology, Cincinnati Children's Hospital Medical Center, University of Cincinnati College of Medicine, Cincinnati, \\ $\mathrm{OH}$, United States, ${ }^{2}$ Division of Experimental Hematology and Cancer Biology, Cincinnati Children's Hospital Medical Center, \\ University of Cincinnati College of Medicine, Cincinnati, OH, United States
}

The Adenosine Monophosphate-activated Protein Kinase (AMPK) and the Mechanistic Target of Rapamycin (mTOR) are two evolutionarily conserved kinases that together regulate nearly every aspect of cellular and systemic metabolism. These two kinases sense cellular energy and nutrient levels that in turn are determined by environmental nutrient availability. Because AMPK and mTOR are kinases, the large majority of studies remained focused on downstream substrate phosphorylation by these two proteins, and how AMPK and mTOR regulate signaling and metabolism in normal and disease physiology through phosphorylation of their substrates. Compared to the wealth of information known about the signaling and metabolic pathways modulated by these two kinases, much less is known about how the transcription of AMPK and mTOR pathway genes themselves are regulated, and the extent to which AMPK and mTOR regulate gene expression to cause durable changes in phenotype. Acute modification of cellular systems can be achieved through phosphorylation, however, induction of chronic changes requires modulation of gene expression. In this review we will assemble evidence from published studies on transcriptional regulation by AMPK and mTOR and discuss about the putative transcription factors that regulate expression of AMPK and mTOR complex genes.

Keywords: AMPK, mTOR, transcription, signaling, metabolism

\section{INTRODUCTION}

Adenosine Monophosphate-activated Protein Kinase (AMPK) is a serine-threonine kinase that exist as a heterotrimer of catalytic $\alpha$ and regulatory $\beta$ and $\gamma$ subunits (Davies et al., 1994; Mitchelhill et al., 1994). Mammals express two catalytic $\alpha 1$ and $\alpha 2$ subunits, two regulatory $\beta 1$ and $\beta 2$ subunits and three additional nucleotide-binding regulatory $\gamma 1, \gamma 2$, and $\gamma 3$ subunits genes (Viollet et al., 2010; Carling et al., 2012; Hardie, 2014a). The N-terminus of the $\alpha$ subunits contain the catalytic domain as well as a phosphorylation site for upstream kinases that regulate its activity (Crute et al., 1998). The $\gamma$ subunits bind to adenosine monophosphate/adenosine diphosphate AMP/ADP and play a regulatory role, while the conserved C-terminus of the $\beta$ subunit interacts with the $\alpha$ and $\gamma$ subunits and is required for AMPK complex formation (Spasic et al., 2008; 
Dasgupta and Milbrandt, 2009). The seven AMPK subunits are expressed more or less ubiquitously. However, each of the twelve possible $\alpha \beta \gamma$ AMPK complex display considerable variation in tissue-specific expression, subunit association, subcellular localization and function (Quentin et al., 2011; Dasgupta et al., 2012). Two upstream kinases - liver kinase B1 (LKB1) Serine/threonine kinase 11 (STK11) and calcium calmodulindependent protein kinase kinase $\beta(\mathrm{CaMKK} \beta)$ phosphorylate the $\gamma$ subunits to fully activate AMPK (Hawley et al., 2003, 2005; Shaw et al., 2004; Hurley et al., 2005; Oakhill et al., 2010, 2011; Xiao et al., 2011). LKB1 exists in a ternary complex with STRAD (STE20-related adaptor) and CAB39/MO25 (mouse protein 25), and LKB1 activity in the complex is 10-fold higher than LKB1 alone (Baas et al., 2003). While LKB1 activates AMPK in response to AMP/ADP, CaMKK $\beta$ activates AMPK in response to $\mathrm{Ca}^{2+}$. Both pathways can act in isolation or synergistically (Woods et al., 2005). The interaction of LKB1 with the AMPK complex has been shown to be facilitated by the cytoplasmic protein AXIN (Zhang et al., 2013), which also interacts with numerous other proteins. Needless to say that transcriptional regulation of the two upstream AMPK kinases could also determine AMPK activation.

The mTOR kinase exists is two distinct complexes mTORC1 and mTORC2. The C1 complex is composed of five proteins - mTOR kinase, RAPTOR (regulatory-associated protein of mTOR), mLST8 (mammalian lethal with Sec13 protein 80 ), PRAS40 (proline-rich AKT substrate $40 \mathrm{kDa}$ ), and Deptor (Dep-domain containing mTOR-interacting protein). The C2 complex is composed of six proteins - mTOR kinase, RICTOR (rapamycin-insensitive companion of mTOR), mSIN1 (mammalian stress-activated protein kinase interacting protein), Protor-1 (protein observed with Rictor-1), mLST8 and Deptor (Laplante and Sabatini, 2009, 2013; Saxton and Sabatini, 2017). In some tissues, a negative feedback from mTORC1 controls mTORC2 such that mTORC1 activation reduces mTORC2 activity.

Excellent reviews have been written on the signaling mechanisms regulated by AMPK and mTOR (Hardie, 2014b; Hardie et al., 2016; Carling, 2017; Garcia and Shaw, 2017). Therefore, we will not elaborate on this topic here. Instead, we will emphasize on the transcriptional regulation of the AMPK mTOR pathway genes and how these two pathways regulate gene expression, beyond signaling.

\section{AMPK AND mTOR PATHWAY GENES}

The genes that encode the seven subunits of AMPK in mammals are Prkaa1 ( $\alpha 1)$, and Prkaa2 ( $\alpha 2)$, Prkab1 ( $\beta 1)$, Prkab2 $(\beta 2)$, Prkag1 ( $\gamma 1$ ), Prkag2 ( $\gamma 2)$, and Prkag3 ( $\gamma 3$ ) (Viollet et al., 2010; Carling et al., 2012; Hardie, 2014a). The rooted trees of the $\alpha$ and $\beta$ subunits suggest that vertebrate Prkaa1/a2 and Prkab1/b2 genes arose by duplications of ancestral genes in lower eukaryotes (Rider, 2016). With one known exception, homologs of AMPK subunits are present in all living organisms indicating that AMPK subunits were selected early in evolution (Lin and Hardie, 2018). AMPK subunits have been reported in the fruit fly Drosophila melanogaster, the nematode Caenorhabditis elegans, the budding yeast Saccharomyces cerevisiae, the flowering plant Arabidopsis Thaliana and other plants (Polge and Thomas, 2007; Emanuelle et al., 2015), and the primitive protozoon Giardia lamblia. The lone exception known so far is the unicellular eukaryotic microsporidian Cephalitozoon cuniculi whose genome does not seem to encode any Prkaa AMPK gene (Katinka et al., 2001; Miranda-Saavedra et al., 2007). The Drosophila genome encodes three AMPK subunits in total - Dmel/Ampka, Dmel/alc (Alicorn or Ampkb), and Dmel/SNF4Ag (FlyBase). C. elegans express two catalytic $\alpha$ subunits (Aak1 and Aak2), two $\beta$ subunits (Aakb1 and $A a k b 2$ ), and five putative $\gamma$ subunits (Aakg1-5) (WormBase version Ws238). In the budding yeast AMPK subunits are encoded by five genes - Snf1a ( $\alpha$ subunit), Sip1, Sip2, and Gal83b ( $\beta$ subunits) and Snf4g ( $\gamma$ subunit) (Hedbacker and Carlson, 2008). In Arabidopsis the SNF1-related kinase 1 (Snrk1), a homolog of yeast $S n f 1$ and mammalian Prka are transcribed by two typical $\alpha$ subunits (Kin10 and Kin11), two $\beta$ subunits, one $\gamma$ subunit along with two atypical subunits - $\beta 3$ and $\beta \gamma$ (Emanuelle et al., 2015). In addition to the AMPK holoenzyme, upstream kinases that are required for full activation of AMPK are also preserved across species. In mammals these upstream kinase genes are Stk11 (Lkb1) and Camkk2. Their homologs in lower eukaryotes include Par4 in C elegans, Dmel/Lkb1 in D. melanogaster, Pak1, Tos3, and Elm1 in S. cerevisiae, and Grik1 and Grik2 in A. thaliana (Hawley et al., 2003; Hong et al., 2003; Shaw et al., 2004; Shen et al., 2009).

Similar to AMPK which is a multimeric complex, the mTORC1 complex contains five proteins in mammals. The genes encoding these five subunits are Mtor, Raptor, Deptor, Lst8, and Akt1s1 (PRAS40). The mTORC2 complex which is composed of six proteins are encoded by Mtor, Rictor, Sin1, Lst8, Prr5l (PROTOR2), and Deptor. Akin to mammals, $S$. Cerevisiae also have TORC1 and TORC2 complexes (Loewith and Hall, 2011) including homologs of Raptor (Kog1), mLST8 (Lst8), Rictor (Avo3), and mSin1 (Avo1), although additional components are specific to yeast or mammals (Saxton and Sabatini, 2017). In C elegans and D. melanogaster, the C1 and C2 genes are encoded by Tor, Raptor, Lst8, Rictor, and $\operatorname{Sin} 1$. Beyond this, there appears to be a degree of unexplained incongruity among organisms in the evolution of the mTOR complex genes. While the protist Dictyostelium discoideum (unicellular common slime mold, a species of soil-dwelling amoeba) encodes all five mTORC1/C2 genes, all plants encode the Tor, Raptor, Lst8 genes. Other unicellular organisms such as the diatom Phaeodactylum tricornutum and the intestinal parasite Giardia intestinalis encode only mTORC1 genes, while the free-living ciliates such as Tetrahymena thermophila encodes only TORC2 genes. Breaking the rule among lower organisms, the free-living unicellular protist Naegleria gruberi and the human parasite Leishmania major express genes for both TORC1 and C2 complex. The malarial parasite Plasmodium falciparum seems to be an exception that does not encode any mTOR complex genes (van Dam et al., 2011). Thus, it appears that while some lower organisms and plants have adapted and evolved successfully with just one TOR complex, perhaps specific nutritional control mechanisms and environmental pressures 
necessitated the presence of both mTORC1 and C2 genes in other organisms.

\section{THE AMPK-mTORC1 SIGNALING AXIS}

Mechanistic Target of Rapamycin1 is an anabolic kinase essential for the biosynthesis of key macromolecules such as protein, lipid and nucleotides (Laplante and Sabatini, 2009; Hindupur et al., 2015; Saxton and Sabatini, 2017). AMPK on the other hand functions to check mTORC1 activity when energy and raw materials for macromolecule production becomes limiting, and as a catabolic enzyme to simultaneously augment glucose import and energy production through glycolysis and mitochondrial oxidative phosphorylation (Mihaylova and Shaw, 2011; Hardie, 2014a; Dasgupta and Chhipa, 2016).

Adenosine Monophosphate-activated Protein Kinase downregulates mTORC1 by two independent mechanisms through phosphorylation of the tumor suppressor Tuberous Sclerosis Complex 2 (TSC2) and RAPTOR. Extensive literature exists on this area (Laplante and Sabatini, 2009, 2013; Mihaylova and Shaw, 2011; Hindupur et al., 2015; Dasgupta and Chhipa, 2016; Saxton and Sabatini, 2017; Herzig and Shaw, 2018), and therefore the signaling axis will only be outlined here. Growth factor signaling loads GTP to the small GTPase called Rheb (Ras homolog enriched in brain), that activates mTORC1 on the lysosomal surface. TSC which is a GTPase activating protein (GAP) for Rheb, converts Rheb-GTP to Rheb-GDP, and thereby inhibits mTORC1 activity (Saxton and Sabatini, 2017). Upstream of TSC, growth factor signaling through Akt, Erk and other kinases phosphorylate TSC to inhibit its GAP activity, and thus enabling mTORC1 activation. On the other hand, under various conditions including energy stress, AMPK phosphorylates TSC2 to enhance its GAP activity causing mTORC1 inhibition (Inoki et al., 2003). While growth factor signaling-induced mTORC1 activation is controlled by AMPK-TSC2 interaction, amino acidinduced mTORC1 activation is controlled by AMPK-RAPTOR interaction (Gwinn et al., 2008). Amino acid adequacy allows activation of the RAG family of small GTPases which binds to RAPTOR and recruits mTORC1 to the lysosome for further activation by Rheb-GTP (Kim et al., 2008; Sancak et al., 2008). During energy stress, AMPK phosphorylates RAPTOR to directly inhibit RAPTOR-mTOR interaction and mTORC1 activation. Although AMPK is localized in nucleus or cytoplasm under various physiological stress, a recent study showed its presence in late endosomes/lysosomes, suggesting that lysosomes serve as a site for AMPK/mTORC1 signaling (Zhang et al., 2014). The preferential requirement of TSC2 versus RAPTOR for mTORC1 regulation under various physiological and pathological contexts remains to be fully understood.

\section{PROTEIN ABUNDANCE AS A DETERMINANT OF KINASE FUNCTION}

Protein phosphorylation by kinases is one of the most widely studied post-translational modifications (PTM) (Levy et al.,
2012). While significant effort has been given to identify phosphosites on kinase substrates and investigate the functional consequences of site-specific phosphorylation, the abundance and stoichiometry of kinases and substrates as functions of proteins are less appreciated (Levy et al., 2012). Although substrate phosphorylation is a regulated process where substrates, kinases and phosphatases are organized via adaptor and scaffold proteins (Bhattacharyya et al., 2006; Scott and Pawson, 2009), a more abundant kinase or a substrate are indeed more likely to come across each other than less abundant proteins (Lienhard, 2008). On the other hand, less abundant proteins can be focally concentrated on the surface of cytosolic organelles such as lysosomes or the endoplasmic reticulum to achieve high level of activity. Kinase-substrate stoichiometry is also crucial - the probability of an abundant substrate to be optimally phosphorylated becomes low if its kinase is suboptimally expressed (Wu et al., 2011; Levy et al., 2012). Although protein abundance at a given time can be regulated at multiple levels such as translation efficiency and turnover rates, transcription rate is also likely to be a key determining factor (Vogel and Marcotte, 2012; Li et al., 2014; Liu et al., 2016). Is transcription of kinases and its context-specific substrates coordinated? How a kinase and its specific substrates are made available in sufficient and proportional quantities in response to an environmental input? To the best of our knowledge, there are no in-depth studies investigating whether and how subunit abundance of AMPK and mTOR complexes are regulated in cell-type specific and context dependent manner, and how that impacts the inhibitory effect of AMPK on mTORC1. Transcription is an highly regulated and complex process with TFs binding up to several kilobases upstream and downstream of the transcription start site of genes, and co-activators and co-repressors binding to distant enhancers (sometimes located on different chromosomes) that loop in to modulate transcription efficiency (Chen and Rajewsky, 2007). Inclusion of all these factors to determine how TFs selforganize and identify binding sites to regulate transcription is not only a formidable task but would require a comprehensive review on this topic itself. Instead, in the next section, we discuss about the transcription factors that bind to cis regulatory elements proximal to transcription start sites of the AMPK and mTOR pathway genes.

\section{TRANSCRIPTION FACTORS REGULATING AMPK AND mTOR PATHWAY GENE EXPRESSION}

The potential TF binding sites (TFBSs) can be predicted using the known and inferred motifs, represented as position-specific scoring matrices (PSSMs) derived from the various binding models such as protein-binding microarrays (PBMs), highthroughput SELEX (HT-SELEX), and manually curated models including JASPAR ${ }^{1}$ and/or TRANFAC ${ }^{2}$ (Orenstein and Shamir, 2014; Hombach et al., 2016). Due to the presence of multiple

\footnotetext{
${ }^{1}$ http://jaspar.genreg.net

${ }^{2}$ http://genxplain.com/tf_class
} 
TFs in more than one binding model source, computationally predicted sites can include many false hits. We therefore collected human TF-binding locations from the ENCODE ChIP-seq hg38 dataset $(\mathrm{v} 3)^{3}$. This dataset contains "in vivo" TF binding peaks from 1256 experiments representing 340 TFs in 129 cell types. For the sake of simplicity, we have only considered peaks supported by at least 4 cell types and found within the $2 \mathrm{~Kb}$ upstream and the $1 \mathrm{~Kb}$ downstream regions of the start site where most of the TF binding sites (TFBS) are located. We would like to recognize that although in most TF binding site (TFBS) distribution studies, the most relevant TFBSs are generally located $\pm 2 \mathrm{~Kb}$ from the TF start site, more complex regulatory circuits may be constructed which are beyond the scope of this review. ChIP-seq has been instrumental in the examination of TF-binding sites (Johnson et al., 2007). Caveats about using ChIP-seq data are that the method can clearly pick up indirect interactions (e.g., the ChIP antibody binds to a TF which instead of directly interacting with DNA interacts to another DNA-bound TF), and many antibodies are not ChIP-grade and can cross-react. Another limitation of ENCODE or similar databases such as ChIP-ATLAS, Cistrome, and ReMap-ChIP is that all these databases are built upon the availability of ChIP-grade antibodies, and therefore several genuine TFs could be missed for which tools are not yet available. Notwithstanding these cautions, we examined ENCODE ChIPseq data to identify potential TFs for the following genes: Prkaa1, Prkaa2, Prkab1, Prkab2, Prkag1, Prkag2, Prkag3, Stk11, Strada, Cab39 (MO25), Camkk2 in the AMPK pathway, and Tsc1, Tsc2, Rptor, Rictor, Mtor, Mlst8, Akt1s1 (PRAS40), Mapkap1 (SIN1), Prr5 (PROTOR), Rheb, Rraga (RAGA), Rragb (RAGB), Ragc (RAGC), and Ragd (RAGD) in the mTOR pathway. This analysis revealed that Prkab1, Prkab2, Prkag1, and the Stk11 (LKB1) binding partners Cab39 and Strada in the AMPK pathway (Figure 1), and Mtor, Mapkap1, Rraga, Rragc, Rptor, and Tsc2 in the mTOR pathway (Figure 2) have the highest number (10 or more) of TFs. On the contrary, Prkaa2, Prkag2, Prkag3, Stk11, and Camkk2 in the AMPK pathway (Figure 1), and Akt1s1, Tsc1, Rragd and Prr5 in the mTOR pathway (Figure 2) are transcribed by the fewest number (1-4) of TFs. The genes with the fewest number (only 1) of assigned TFs were Camkk2, Akt1s1, Tsc1, while the genes with the highest number (21-23) of assigned TFs were Prkag1, Prkab1, Strada, Rraga and Tsc2.

A simple explanation of these results is that transcriptional regulation of some genes of the AMPK and mTOR pathways are more flexible and more adaptive with several TFs able to initiate transcription under various cues, while regulation of other genes with just one or two TFs is tight and critically depend on the abundance of these TFs. An alternative explanation is that one or two TFs are sufficient for optimal transcription of some genes, while other genes require cooperative interaction of multiple TFs for optimal transcription. It is also possible that the one or two TFs that we identified for some genes in the $2 \mathrm{~Kb}$ upstream and $1 \mathrm{~Kb}$ downstream region of the TSS are actually insufficient and require coordination of coactivators and distant enhancers. Another intriguing observation that is apparent from Figures 1, 2 is that there seems to

${ }^{3} \mathrm{https}: / /$ www.encodeproject.org

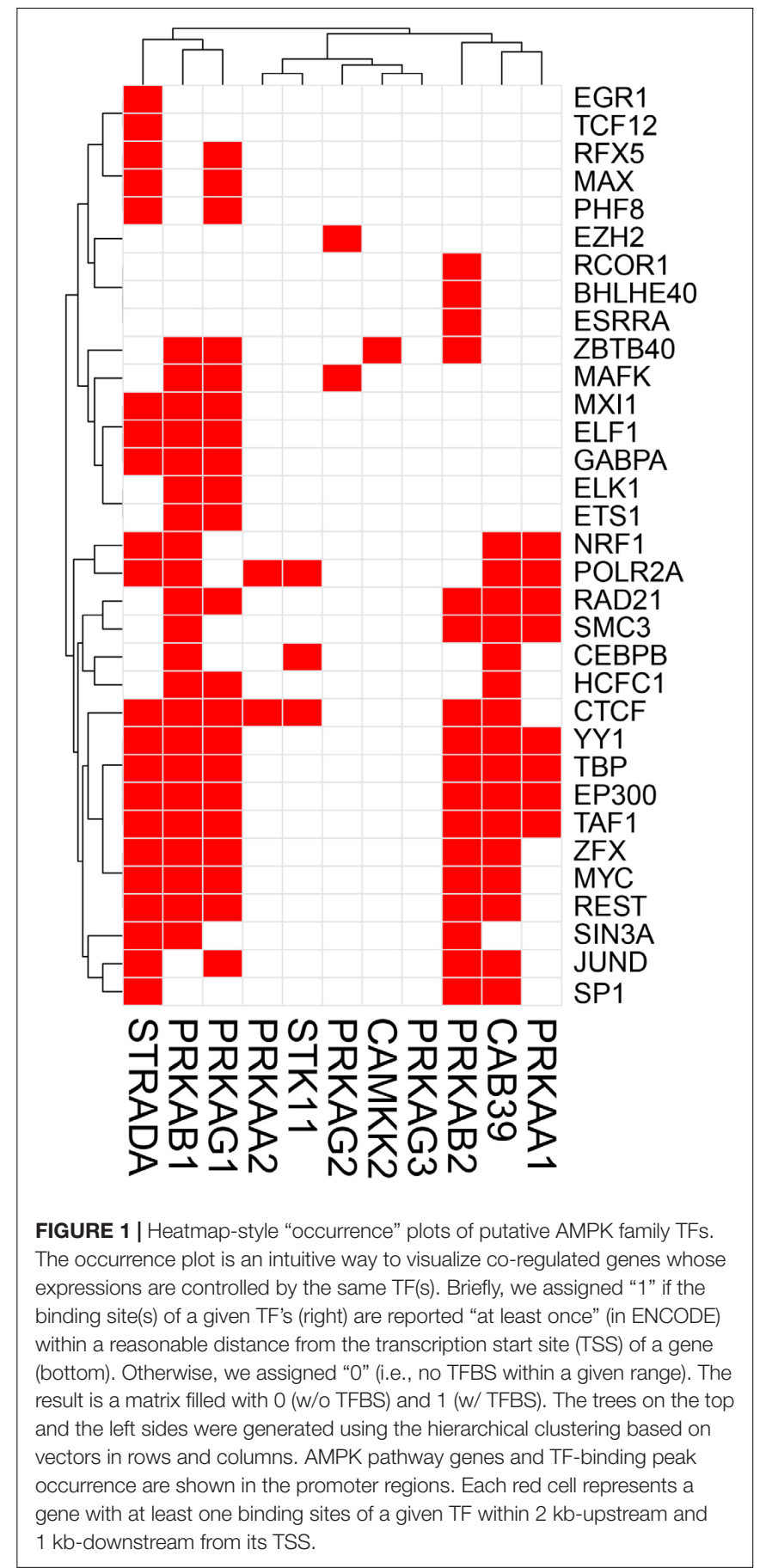

be a cluster of common TFs that regulate multiple genes of both AMPK and mTOR pathway. For example, the TFs YY1, TBP, EP300, RAD21, REST, Myc, SIN3A, CTCF, and TAF1 has binding sites in half of the twenty-five AMPK and mTOR pathway genes. We speculate that environmental cues probably converge on common TFs to regulate transcription of AMPK and mTOR pathway genes in a coordinated fashion such that the required abundance and stoichiometry is maintained for optimal signaling output. 


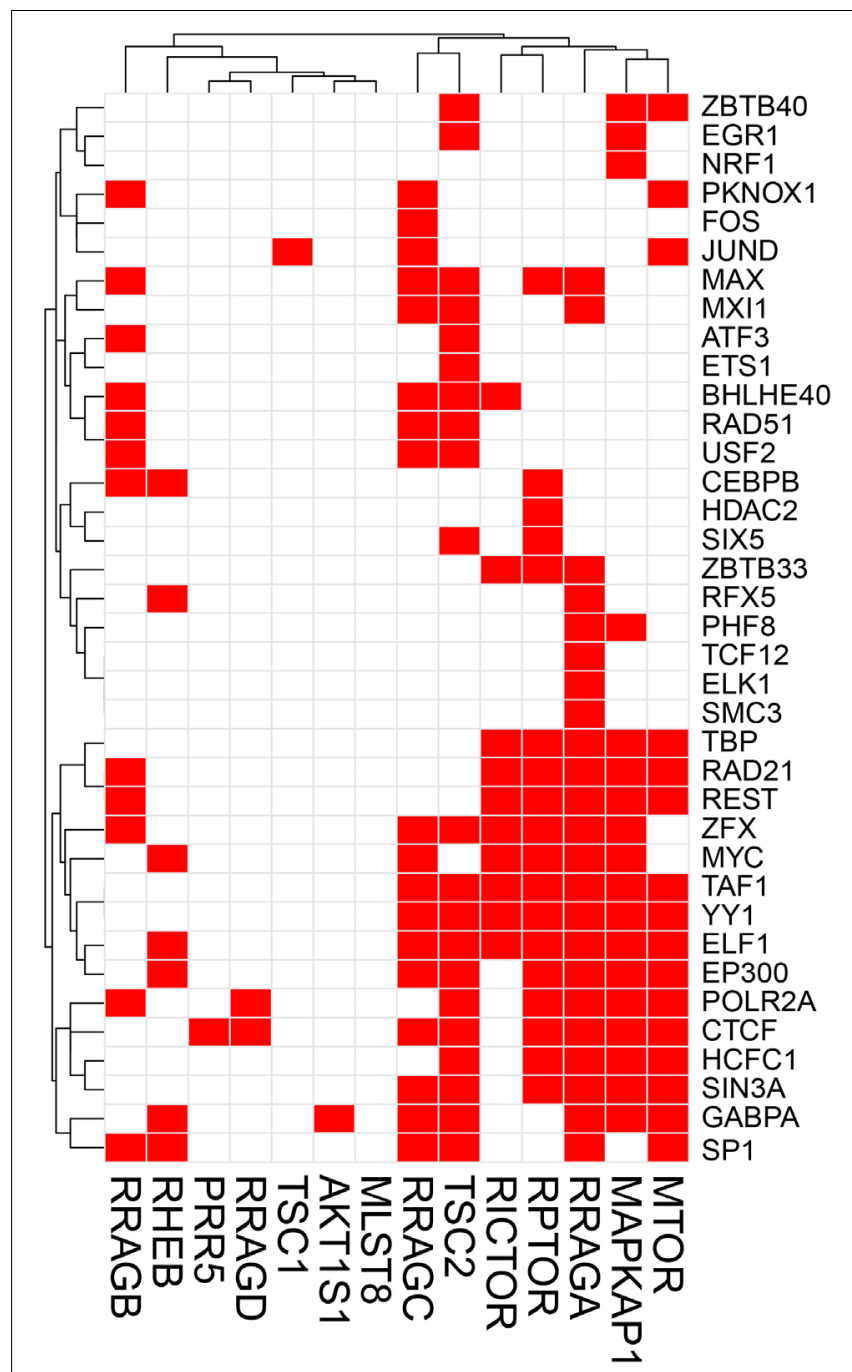

FIGURE 2 | Heatmap-style "occurrence" plots of putative mTOR family TFs. The occurrence plot is an intuitive way to visualize co-regulated genes whose expressions are controlled by the same TF(s). Briefly, we assigned " 1 " if the binding site(s) of a given TF's (right) are reported "at least once" (in ENCODE) within a reasonable distance from the transcription start site (TSS) of a gene (bottom). Otherwise, we assigned "O" (i.e., no TFBS within a given range). The result is a matrix filled with 0 (w/O TFBS) and 1 (w/ TFBS). The trees on the top and the left sides were generated using the hierarchical clustering based on vectors in rows and columns. mTOR pathway genes and TF-binding peak occurrence are shown in the promoter regions. Each red cell represents a gene with at least one binding sites of a given TF within $2 \mathrm{~kb}$-upstream and $1 \mathrm{~kb}$-downstream from its TSS.

\section{AMPK MAY CONTROL GENE EXPRESSION THROUGH METABOLITES OF INTERMEDIARY METABOLISM}

It is now well-established that both metabolic enzymes and metabolites synthesized in intermediary metabolism directly or indirectly impact gene expression. DNA itself and DNAbinding histones are modified and regulated by several mechanisms that uses metabolites generated in intermediary metabolism (Etchegaray and Mostoslavsky, 2016; van der Knaap and Verrijzer, 2016; Nieborak and Schneider, 2018). These include nicotinamide adenine dinucleotide (NAD) (used in SIRT mediated histone deacetylation and histone polyADPribosylation) (Vaquero et al., 2006; Michishita et al., 2008; Kawahara et al., 2009; Nakahata et al., 2009; Zhong et al., 2010; Barber et al., 2012; Etchegaray et al., 2013; Imai and Guarente, 2014), flavin adenine dinucleotide FAD (used in lysine-specific histone demethylation by LSD1/2) (Shi et al., 2004; Shi and Whetstine, 2007; Ciccone et al., 2009; Karytinos et al., 2009; Dimitrova et al., 2015), acetyl co-A (used in histone acetylation), S-adenosylhomocysteine (SAM, used in DNA methylation) (Takusagawa et al., 1996; Mentch et al., 2015), $\alpha$-ketoglutarate (used to regulate DNA methylation through activation of the TET and JMJD family of DNA demethylases) (Xiao et al., 2012; Pastor et al., 2013), succinyl CoA (used in succinylation of the histone acyltransferase KAT2A) (Wang et al., 2017), UDP-GlcNAc (used O-GlcNAcylation of histones) (Sakabe et al., 2010; Fujiki et al., 2011; Nardini et al., 2013; Lewis and Hanover, 2014), among others. Therefore, the activity of metabolic enzymes that regulate intermediary metabolic cycles in essence controls DNA and histone modifications and thereby gene expression. Besides generating ATP from glucose oxidation to maintain energy homeostasis, AMPK enhances glycolysis and glucose oxidation through the TCA cycle and mitochondrial oxidative phosphorylation by various mechanisms. It increases glucose transporter expression and cell surface translocation (Kurth-Kraczek et al., 1999; Xi et al., 2001; Kishton et al., 2016; Siques et al., 2018), activates phosphofructokinase 2 (PFK2) (Marsin et al., 2000), and cAMP Responsive Element Binding Protein 1 (CREB1) (Chhipa et al., 2018), and transcriptionally upregulates Peroxisome proliferatoractivated receptor gamma coactivator 1-alpha (PGC1 $\alpha$ ) (Terada et al., 2002; Suwa et al., 2003). NAD is generated from pyruvate especially in highly glycolytic lactate producing cells, while both FAD and NAD are produced in the mitochondrial electron transport chain complex I and II (Rogatzki et al., 2015). Acetyl co-A, $\alpha$ ketoglutarate and succinyl CoA are all produced in the TCA cycle, and UDP-GlcNAc is produced in the hexosamine pathway that originates from glucose phosphorylation in glycolysis (Jeremy et al., 2002). Therefore, environmental cues that activate AMPK can in turn regulate gene expression through glucose metabolism-derived metabolites (Figure 3).

Glucose metabolism impacts gene expression. At the systemic level, glucose stimulates insulin expression in the pancreas (Schuit et al., 1988; Rorsman and Braun, 2013). In the liver, glucose induces glucose transporter expression, glycolytic and lipogenic enzymes (Rui, 2014; Han et al., 2016), and in the muscle it induces glucose transporters for insulin-induced glucose uptake (Klip and Paquet, 1990; Saltiel and Kahn, 2001). However, glucose is metabolized by every cell outside these three primary metabolic organs. What is the impact of glucose on gene expression at the cellular level outside the primary metabolic organs? The effects of AMPK on glucose metabolismdependent gene expression could be acute or chronic. In the large majority of published studies, this effect of AMPK has 


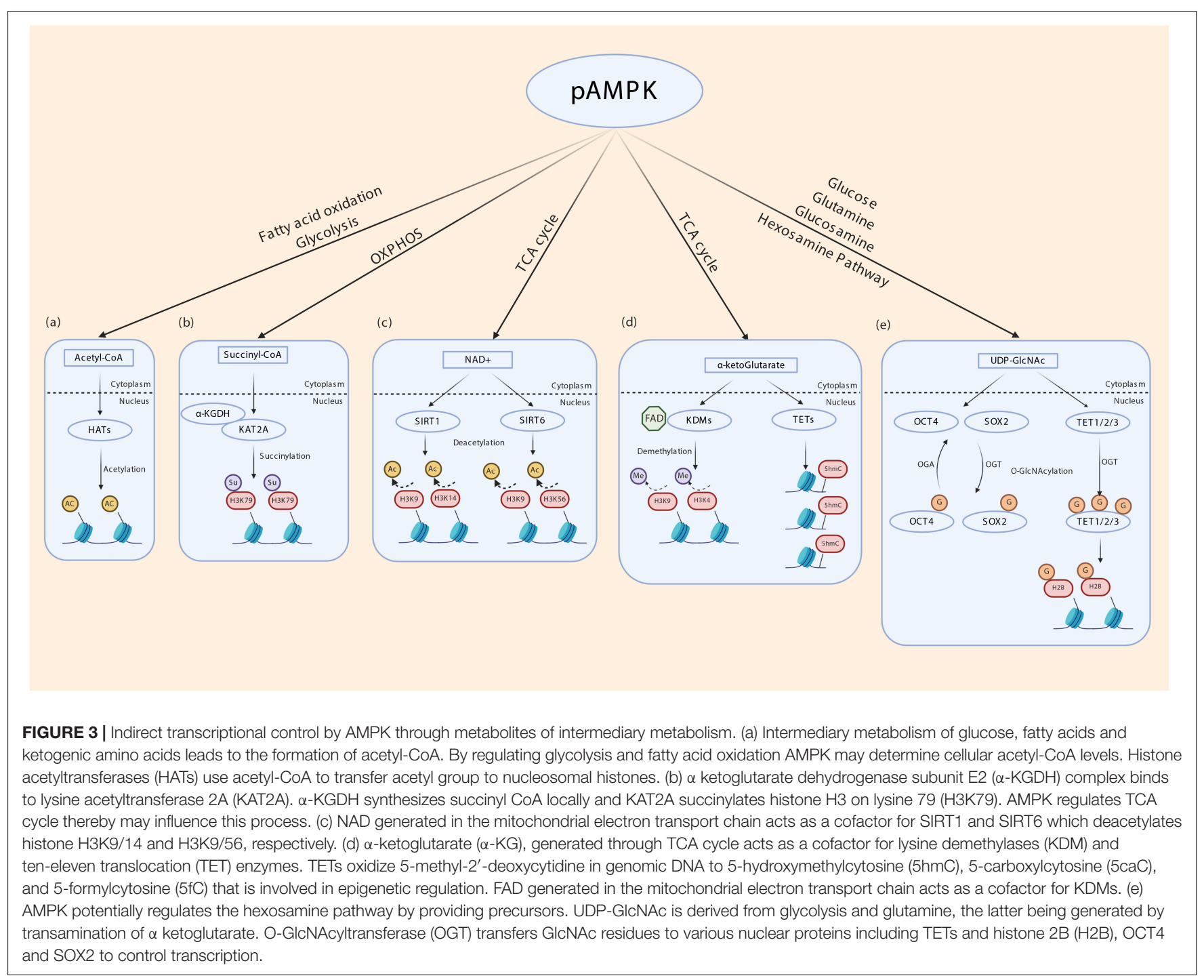

been studied in glucose-starved cells that were acutely reexposed to glucose in vitro, an experimental condition that reduces AMPK activity in most if not all normal cells. In several cancer cells, however, high basal AMPK activity is insensitive to such manipulation of glucose levels (Chhipa et al., 2018). While acute exposure of glucose-starved cells depresses AMPK activation, active AMPK levels quickly reach steady state levels, sometimes in minutes. It is imperative to understand that following glucose addition, because of the steady flux of glucose import and consumption through glucose phosphorylation, intracellular glucose levels are not reduced significantly by the time steady state levels of active AMPK levels have been reached. What is the need for AMPK activity to resurge so quickly when the cells are actively metabolizing glucose? And what role active AMPK plays during steady state cellular glucose metabolism in normal and tumor cells? It will be interesting to learn if glucose metabolism-dependent global gene expression is affected in the absence of AMPK. If AMPK is required for the optimal generation of chromatin modifying metabolites in glycolysis and TCA cycle, the prediction is that global gene expression will be significantly altered in AMPK null cells.

Recent reports demonstrating the involvement of AMPK in regulating the tumor suppressor gene folliculin (FLCN) came from Collodet et al. (2019). In this study, the authors have shown that AMPK induces FLCN expression via the transcription factors transcription factor EB (TFEB) and transcription factor binding to IGHM enhancer 3 (TFE3) independent of mTOR. This is one of the few reports that demonstrate the mTORindependent effects of AMPK on the transcription factors TFEB and TFE3. mTOR independent effects of AMPK on these TFs was also recently reported by El-Houjeiri et al. (2019) in which the authors showed that TFEB and TFE3 regulate innate immune response via AMPK/FLCN signaling axis. The role of AMPK in regulating TFEB levels was also shown by Young et al., in mouse embryonic stem cells (ESCs). ESCs lacking AMPK were normal in the pluripotent state, but developed profound defects during differentiation. TFEB was found to be the most significantly 
downregulated gene in AMPK deficient cells leading to reduced endolysosomal activity. Similar defects were seen in TFEB null ESCs linking TFEB and diminished lysosomal activity to germ cell specification (Young et al., 2016).

\section{mTORC1 REGULATION OF TRANSCRIPTION}

Many TFs require post-translational modifications (PTM) for activity, nuclear/cytoplasmic translocation, interaction with binding partners including other TFs, stability and DNA binding (Benayoun and Veitia, 2009; Filtz et al., 2014). These include phosphorylation, glycosylation, methylation, acetylation, sumoylation and ubiquitination. Phosphorylation is a straight forward and reversible modification that transmits signal from extracellular cues through growth factor signaling to TF activity. Phosphorylation can also cooperate with or antagonize other PTM to modulate TF activity. Several TFs have been shown to be regulated by mTORC1 - this includes yin yang 1 (YY1), sterol regulatory element binding proteins SREBPs, signal transducer and activator of transcription STAT3, PGC1 $\alpha$, hypoxia inducible factor 1 alpha (HIF $1 \alpha)$, peroxisome proliferator-activated receptors PPAR $\gamma / \alpha$ and TFEB (Laplante and Sabatini, 2013). Nuclear Lipin 1 binds to SREBPs and impairs SREBP-mediated transcription of lipogenic genes. mTORC1 phosphorylates Lipin 1 to cause its nuclear exclusion, thus controlling lipogenic gene expression (Laplante and Sabatini, 2013). In response to excess amino acids or ciliary neurotrophic factor (CNTF) signaling, mTORC1 directly phosphorylates STAT3 at S727 to promote its transcriptional activity (Yokogami et al., 2000; Kim et al., 2009). The SREBP family of bHLH TFs regulate lipogenesis. Multiple studies have shown that mTORC1 increases lipogenesis by augmenting SREBP1 mRNA and protein levels, processing and nuclear enrichment ( $\mathrm{Li}$ et al., 2010, 2011; Wang et al., 2011; Yecies et al., 2011; Bakan and Laplante, 2012; Owen et al., 2012). A recent study by Li et al. (2019) has identified STAT5 phosphorylation by mTORC1 in promotion of SREBP1 transcriptional activity, thereby establishing a molecular mechanism by which mTORC1 controls SREBP1. The role of mTORC1 in PPAR $\gamma$-mediated adipogenesis is controversial. While some studies show a positive effect on adipogenesis, others show a negative effect of mTORC1 on adipogenesis (Kim and Chen, 2004; Polak et al., 2008; Laplante and Sabatini, 2012). Through its downstream kinase S6K2, mTORC1 inhibits PPAR $\alpha$ activity and PPAR $\alpha$ - mediated hepatic ketogenesis (Sengupta et al., 2010; Kim et al., 2012), however, evidence for a direct phosphorylation event in this phenomenon is lacking. During hypoxia, mTORC1 possibly increases HIF1 $\alpha$ transcription although mechanisms are unknown (Laughner et al., 2001; Hudson et al., 2002; Brugarolas et al., 2003; Duvel et al., 2010). Lysosomes that act as scaffold for AMPK-mTORC1 interaction responds to environmental signals and take part in stress response during which rapid expansion of lysosomal membrane takes place. mTORC1 phosphorylates TFEB which triggers 14-3-3 binding and cytoplasmic sequestration of TFEB. During nutrient stress which inhibits mTORC1, TFEB is released, translocates to the nucleus to coordinate lysosomal membrane synthesis (Martina et al., 2012; Roczniak-Ferguson et al., 2012; Settembre et al., 2012). mTORC1 was also reported to orchestrate mitochondrial biogenesis through its interaction with PGC1 $\alpha$ and YYI (Cunningham et al., 2007; Koyanagi et al., 2011). It is well known that mTORC1 is present in the nucleus. However, how mTORC1 interacts with PGC1 $\alpha$ and YYI to coordinate mitochondrial biogenesis remains unclear. mTOR regulation of transcription is illustrated in Figure 4. Together, these studies indicate that although not all mechanisms are fully understood, the effect of mTORC1 on regulating TF activity is unequivocal.

\section{AMPK REGULATION OF TRANSCRIPTION: ROLE BEYOND SIGNALING}

\section{Transcriptional Regulation of Monosaccharide Sensing in Yeast and Mammalian Cells}

Adenosine Monophosphate-activated Protein Kinase's role in direct control of gene expression through $\mathrm{TF}$ regulation has been documented from the budding yeast Saccharomyces to mammalian cells. In the budding yeast Saccharomyces cerevisiae, glucose suppresses expression of a set of genes that are used to catabolize carbon sources other than glucose in glucose-limited growth conditions. Derepression/activation of glucose-repressed genes was found to rely on Snf1-dependent phosphorylation of multiple serine residues on the zinc finger TF Mig1 (Treitel et al., 1998; Smith et al., 1999). In contrast to yeast, mammalian cells heavily rely on glucose for rapid proliferation and survival. Some mammalian cells can sustain short periods of very low glucose levels in the presence of starch or maltose (Rheinwald and Green, 1974). However, glucose is the principle monosaccharide required for cell division and survival of mammalian cells. Growth of higher eukaryotic cells in secondary glucose sources in the normal physiological context is rare and therefore, whether AMPK plays an analogous role in glucose depleted conditions in higher eukaryotes is unknown. The mammalian ortholog of Mig1 are the Early Growth Response (EGR) family of TFs. It is, however, unknown if AMPK phosphorylates EGR family of TFs in mammalian cells.

\section{Transcriptional Control of Cell Cycle, Proliferation and Survival by AMPK}

The role of AMPK in cell cycle control, proliferation, growth and survival by direct phosphorylation and transcriptional regulation of cell cycle proteins and TFs in the mammalian system is a fundamental yet understudied area in the AMPK field. Moreover, published results in this area need more confirmatory studies to understand the cell type and contextspecific regulation of cell cycle and survival by AMPK. Studies in Saccharomyces cerevisiae, showed that the AMPK homolog Snf1 is required for transcription of genes for growth and survival in low glucose media or alternate carbon sources such as sucrose (Carlson, 1999). During inositol starvation, 


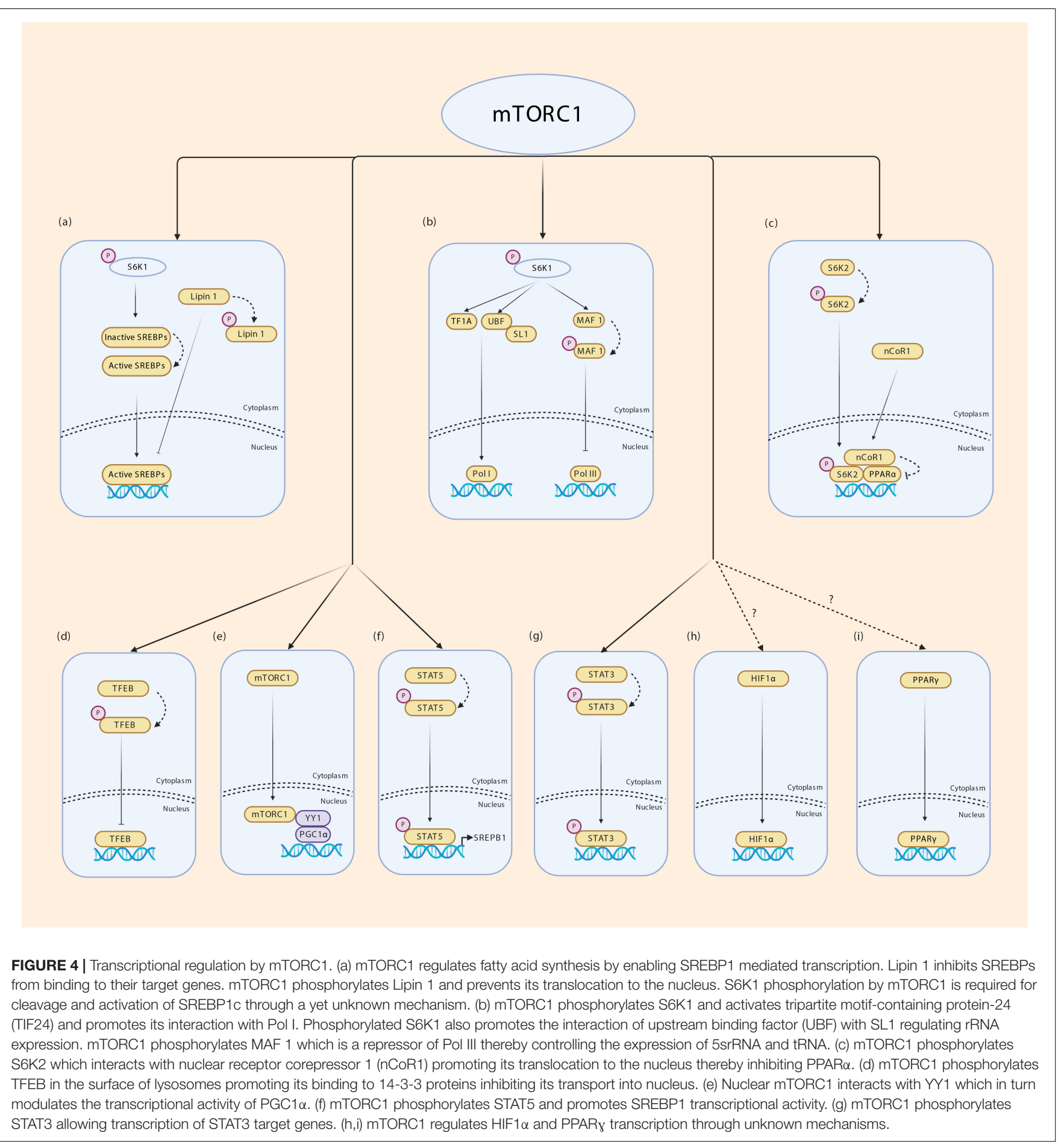

Snf1 phosphorylates histone 3 on S10 to allow recruitment of the acetyltransferase GCN5, DNA unfolding and transcription of INO1 transcription to promote survival (Lo et al., 2001). Histone phosphorylation by AMPK seems to be conserved in mammalian cells, since under various metabolic stresses, AMPK phosphorylated $\mathrm{H} 2 \mathrm{~B}$ on S36 to enhance transcription of survival genes (Bungard et al., 2010). Genetic studies in model organisms confirmed that loss of AMPK causes defects in cell polarity, growth and development of both early plants and animals (Lee et al., 2007; Mirouse et al., 2007; Bartkova et al., 2010; Wang and Kaufman, 2014). Active AMPK localized to the mitotic spindle of mammalian cells (Thaiparambil et al., 2012), although its significance is still unknown. Genome-wide survey of kinases required for mitosis, and genetic screen using $\mathrm{AMPK} \alpha 2$ shRNA identified 28 novel proteins involved in chromosomal segregation, mitosis, cytokinesis and cytoskeletal reorganization 
that were phosphorylated by AMPK (Bettencourt-Dias et al., 2004; Fukuyama et al., 2007; Banko et al., 2011; Stenesen et al., 2013). AMPK was also found to be required for cell cycle progression of mammalian and Drosophila cells (Vazquez-Martin et al., 2009; Bartkova et al., 2010; Banko et al., 2011; Lu et al., 2011). About a decade ago, we reported that nuclear AMPK phosphorylates retinoblastoma protein (RB) to regulate G1-S transition of neural stem cells (Dasgupta and Milbrandt, 2009). RB phosphorylation by AMPK was independently confirmed in glioblastoma cells (Rios et al., 2013). Why a kinase that is known to generally counter growth would inhibit RB to allow proliferation? Whether this is true only in the neuroepithelial compartment or in other cell types outside the neuroepithelial compartment is yet to be determined. Intriguingly, AMPK was found to directly phosphorylate p53 on Ser15 to promote G1 arrest under nutrient stress. P53 is ubiquitinated and degraded to allow cell cycle progression, and its stabilization in dividing cells can lead to apoptosis or senescence (Lavin and Gueven, 2006). Another TF whose transcriptional activity is increased upon phosphorylation by AMPK is FoxO3 (Greer et al., 2007). FoxO family of TFs play important roles in growth factor signaling, proliferation, glucose metabolism and longevity (Lin et al., 1997; Ogg et al., 1997; Nakae et al., 2002; Giannakou et al., 2004; Hwangbo et al., 2004; Paik et al., 2007). AKT phosphorylates and sequesters FoxO family of TFs in the cytoplasm (Brunet et al., 1999; Kops et al., 1999; Tang et al., 2002). AMPK was shown to phosphorylate $\mathrm{FoxO} 3$ on six serine residues in vitro and in two residues (S413 and S588) in endogenous FoxO3 to enhance its transcriptional activity (Greer et al., 2007) toward its target genes including the cell cycle inhibitor p27 (Morgan, 1997; Medema et al., 2000). Therefore, it is conceivable that the contexts in which AMPK may phosphorylate RB, P53 or FoxO are discrete. The cell cycle machinery senses available cellular energy, and ATP depletion by as little as $15 \%$ has been found to cause G1 arrest, and a depletion by 35\% caused G2M arrest of human promyelocytic leukemia cells (Sweet and Singh, 1995). It is not understood if AMPK's role in mitosis is uncoupled from or linked to its energy sensing function. It is possible that basal nuclear AMPK activity phosphorylates a set of TFs to enable cell cycle proliferation when growth conditions are permissive, while a TF code switch during severely restrictive growth conditions signals cell cycle arrest to allow survival. This is an important yet unanswered question, and hopefully analysis of the nuclear phosphoproteomes integrated with single cell RNA-seq of proliferating cells will be able to address this issue.

\section{Transcriptional Control of Glucose and Mitochondrial Metabolism by AMPK}

The requirement of AMPK for optimal glucose metabolism through glycolysis and oxidative phosphorylation has been reported in several cell culture and animal models. We have recently shown that AMPK phosphorylates the TF CREB1 on S133 to orchestrate transcription of HIF1 $\alpha$ and GABPA, which are master regulators of the glycolysis and mitochondrial biogenesis transcriptional programs, respectively (Chhipa et al., 2018). CREB1 regulation by AMPK was also shown previously.
In skeletal muscle, AMPK phosphorylates CREB1 on S133 to activate CREB1-dependent transcription. Interestingly, this is the same site targeted by PKA (Thomson et al., 2010). Thomson et al., showed that AMPK also phosphorylates other TFs such as CREM, ATF1 and CREBL2 in the skeletal muscle. CREB phosphorylation is not required for binding to CREB responsive elements, but it augments recruitment of coactivators such as CBP/p300 (De Cesare and Sassone-Corsi, 2000). Intriguingly, one study showed that AMPK can phosphorylate $\mathrm{CBP} / \mathrm{p} 300$ at $\mathrm{S} 89$ to reduce its interaction with nuclear receptors such as PPAR $\gamma$, thyroid receptor and retinoic acid receptors, but not with other TFs including CREB1, p53, E1A, and GATA1 (Yang et al., 2001). Reduced interaction of coactivators like CBP/P300 with PPAR $\gamma$, seems at odds with the well-established evidence that AMPK promotes mitochondrial biogenesis and oxidative phosphorylation (OXPHOS) through activation of the PPAR $\gamma$ coactivator $1 \alpha$ (PGC1 $\alpha$ ) (Bergeron et al., 2001; Terada et al., 2002; Jorgensen et al., 2005; Reznick and Shulman, 2006; Garcia-Roves et al., 2008; Canto et al., 2010). The transcriptional coactivator PGC1 $\alpha$ is a master regulator of mitochondrial biogenesis and OXPHOS. PGC1 $\alpha$ activates two key nuclear respiratory factors NRF1 and NRF2 that activate the mitochondrial transcription factor TFAM which is essential for mitochondrial DNA replication and transcription of mitochondrial genes (Fisher et al., 1992; Virbasius and Scarpulla, 1994; Scarpulla, 2006). Several studies confirmed that AMPK enhances PGC1 $\alpha$ expression and activity, and PGC1 $\alpha$ - dependent mitochondrial gene expression (Suwa et al., 2003; Jorgensen et al., 2005; Jager et al., 2007; Irrcher et al., 2008; Canto et al., 2009), but the mechanisms remain contested. One study showed direct phosphorylation of PGC1 $\alpha$ by AMPK on T177 and S538 (Jager et al., 2007), however these results need further confirmation. We have shown that in glioblastoma, AMPK promotes mitochondrial metabolism through CREBdependent activation of NRF2 (Chhipa et al., 2018). PGC1 $\alpha$ also controls energy homeostasis and mitochondrial biogenesis by interacting with estrogen-related receptors (ERRs) (Huss et al., 2002; Kamei et al., 2003; Schreiber et al., 2003; Laganiere et al., 2004; Handschin and Spiegelman, 2006; Sonoda et al., 2007; Charest-Marcotte et al., 2010).

Arguments about the role of AMPK in the regulation of glucose metabolism still exist. AMPK activation has been shown to promote expression and cell surface translocation of the glucose transporter GLUT4 through the TF MEF2. On the other hand, PGC1 $\alpha$ was shown to function as a coactivator of the MEF2 to regulate GLUT4 expression and surface translocation (Lin et al., 2002; Knight et al., 2003; Holmes et al., 2005; McGee et al., 2006). Whether AMPK directly phosphorylates MEF2 is uncertain, but it has been proposed that AMPK phosphorylates the GLUT4 Enhancer Factor (GEF) to promote its nuclear translocation and interaction with MEF2 (McGee et al., 2006). Another study linked GLUT4 transcription by AMPK through the HDAC5-MEF2 axis. HDAC5 is a histone deacetylase and a transcriptional repressor. It binds to MEF2 and by removing lysine acetyl marks from histones, inhibits MEF2-dependent transcription. In light of these findings, it is worth noting that nuclear AMPK phosphorylates HDAC5 on S259 and 498 
disrupting its binding to MEF2 and enabling MEF2-dependent transcription of GLUT4 (McGee et al., 2008).

When overwhelming evidence supports the role of AMPK as a survival kinase during energy crisis, some of the findings about its role in systemic glucose homeostasis during energy crisis seems counterintuitive to its role as a survival kinase. When glucose level drops during fasting, liver glycogenolysis produces glucose; if fasting continues beyond glycogen depletion, gluconeogenesis triggers to provide the much-required glucose for tissue function, particularly the brain and red blood cells. While AMPK phosphorylates CREB1 in muscle to enhance its transcriptional activity, it was shown to reduce CREB1dependent gluconeogenesis in the liver (Koo et al., 2005). Following depletion of glycogen-derived glucose production, gluconeogenesis is induced in the liver in periods of energy crisis. Glucagon activates cAMP-PKA signaling during which PKA phosphorylates the CREB1 coactivator called transducer of regulated CREB (CRTC2 or TORC2 not mTORC2) causing its nuclear translocation, CREB1 binding and transcription of key gluconeogenic genes such as phosphoenolpyruvate carboxykinase (PEPCK) and glucose-6-phosphatase (G6P). AMPK was shown to phosphorylate CRTC2 on S171 causing cytoplasmic sequestration through 14-3-3 binding and inhibition of gluconeogenesis (Koo et al., 2005). This study showed that AMPK activation even in the presence of CAMP agonists sequestered CREB regulated transcription coactivator 2 (CRTC2) in the cytoplasm and argued that AMPK inhibits gluconeogenesis even in periods of energy crisis which is known to trigger AMPK activation. This phenomenon seems counterintuitive to AMPK's role as a survival kinase. In fact, the role of CRTC2 in fasting-induced gluconeogenesis and glucose homeostasis has been questioned because fasting-induced glucose homeostasis remained unaffected in CRTC2 knockout mice (Le Lay et al., 2009). Similarly, it is reasonable to assume that AMPK might promote glycogenolysis during starvation. Indeed, initial reports supported this assumption when AMPK was shown to phosphorylate and increase glycogen phosphorylase activity (the rate limiting enzyme for glycogenolysis) (Carling and Hardie, 1989; Young et al., 1996), although this was later disputed by other studies (Viollet et al., 2003a,b; Barnes et al., 2004; Jorgensen et al., 2005). We have conclusively shown that fasting and exercise -induced glycogenolysis in the skeletal muscle (that almost exclusively express $\beta 2$ and not $\beta 1$ subunit) is reduced by over $20 \%$ in the AMPK $\beta 2$ knockout mice (Dasgupta et al., 2012). Together, it seems that AMPK may indeed stimulate glycogenolysis through phosphorylation of glycogen phosphorylase and / or through yet unknown transcriptional control of glycogenolysis.

\section{AMPK Activity in the Nucleus}

Which kinase phosphorylates AMPK in the nucleus or does AMPK get phosphorylated in the cytoplasm before translocating to the nucleus? We and others have shown that AMPK is present in the nucleus. Both $\alpha 1$ and $\alpha 2$ subunits, but the $\alpha 2$ subunit in particular has been found in the nucleus (Salt et al., 1998; Vincent et al., 2001; Leff, 2003; McGee et al., 2003; Kodiha et al., 2007). Unlike the $\alpha 2$, the $\alpha 1$ does not seem to have a nuclear localization signal and its nuclear localization could depend on cytoplasmic-nuclear chaperones. We have shown that active AMPK is present in the nuclei of mouse neural stem cells, and while the regulatory $\beta 2$ subunit was restricted mainly to the cytoplasm, the $\beta 1$ subunit was enriched in the nucleus (Dasgupta and Milbrandt, 2009). Examining glioblastoma clinical samples we observed copious amounts of active AMPK both in the cytoplasm and the nucleus (Chhipa et al., 2018). The presence of the AMPK kinase CAMKK2 has been shown in the nucleus of prostate cancer cells (Karacosta et al., 2012), and nuclear AMPK $\alpha 1$ was recently shown to be phosphorylated by CAMKK in HeLa and A549 lung cancer cells (Vara-Ciruelos et al., 2018). Whether LKB1 is present in the nucleus is unknown. Much work is necessary to understand the mechanisms of AMPK activation in the nucleus.

\section{mTOR Activity in the Nucleus}

Accumulating evidence shows the presence of mTOR in the nucleus. mTOR regulates RNA polymerase (Pol)-mediated transcription either directly in the nucleus or indirectly by regulating nuclear translocation of TFs (Giguere, 2018). It is well known that environmental cues (nutrients) regulate the transcriptional activity of Pol I and Pol III. However the mechanism by which nutrients modulate the activity of Pol I and III was ill-defined until the role of mTOR in Pol I and III-mediated transcription of ribosomal DNA and transfer RNA genes was established (Tsang et al., 2010). mTOR associates with the $45 \mathrm{~s}$ rDNA promoter and $5 \mathrm{~s}$ rDNA and tRNAs genes, thus, regulating ribosome biogenesis and protein synthesis. mTOR controls the transcriptional activity of Pol I and III by phosphorylating TFs and regulating their activity. For e.g., in Saccharomyces cerevisiae, mTORC1 phosphorylates the TF Maf1 through S6K1, thereby controlling Pol-III mediated transcription (Wei et al., 2009). In mammals, mTORC1 phosphorylates TIF1A and UBF, the TFs involved in the formation of Pol I transcription initiation complex (Mayer et al., 2004; Figure 4). Whether cytoplasmic activation of mTORC1 is necessary for its translocation to nucleus or it is activated in the nucleus itself requires further confirmatory studies.

\section{CONCLUDING REMARKS}

Since its discovery as a cytosolic metabolic kinase that purified with and inhibited Acetyl Co-A carboxylase (the rate limiting enzyme for long chain fatty acid synthesis) (Lent and Kim, 1982), we have come a long way to have discovered the many facets of AMPK function in cellular and systemic metabolism, regulation of cell cycle, longevity, stress resistance, tumor pathology, circadian rhythm among other functions. Since the generation of the first AMPK subunit knockout animals, seminal studies have provided evidence on its role in glucose and lipid homeostasis in the liver and skeletal muscle and in type II diabetes. The bulk of AMPK research after its discovery as a key negative regulator of mTORC1 was devoted to understand signaling pathways around the AMPK-mTORC1 axis in normal physiology and pathology, particularly cancer. Despite the important findings 
about AMPK's direct involvement in gene expression and cell cycle control in the nucleus, frank transcriptional regulation by AMPK beyond signaling has remained a less-explored area. Equally important but also poorly understood is how the individual subunits of AMPK are transcriptionally regulated by cellular and environmental cues. Here, we described an abridged summary of TFs that coordinate transcription of AMPK and mTOR pathway genes. We hope that this preliminary report will engender interest in the field to examine the context-dependent transcriptional regulation of the energy sensing AMPK and biosynthetic mTOR pathway genes.

\section{REFERENCES}

Baas, A. F., Boudeau, J., Sapkota, G. P., Smit, L., Medema, R., Morrice, N. A., et al. (2003). Activation of the tumour suppressor kinase LKB1 by the STE20-like pseudokinase STRAD. Embo J. 22, 3062-3072. doi: 10.1093/emboj/cdg292

Bakan, I., and Laplante, M. (2012). Connecting mTORC1 signaling to SREBP-1 activation. Curr. Opin. Lipidol. 23, 226-234. doi: 10.1097/mol. 0b013e328352dd03

Banko, M. R., Allen, J. J., Schaffer, B. E., Wilker, E. W., Tsou, P., White, J. L., et al. (2011). Chemical genetic screen for AMPKalpha2 substrates uncovers a network of proteins involved in mitosis. Mol. Cell 44, 878-892. doi: 10.1016/j. molcel.2011.11.005

Barber, M. F., Michishita-Kioi, E., Xi, Y., Tasselli, L., Kioi, M., Moqtaderi, Z., et al. (2012). SIRT7 links H3K18 deacetylation to maintenance of oncogenic transformation. Nature 487, 114-118. doi: 10.1038/nature11043

Barnes, B. R., Marklund, S., Steiler, T. L., Walter, M., Hjalm, G., Amarger, V., et al. (2004). The 5'-AMP-activated protein kinase gamma3 isoform has a key role in carbohydrate and lipid metabolism in glycolytic skeletal muscle. J. Biol. Chem. 279, 38441-38447. doi: 10.1074/jbc.m405533200

Bartkova, J., Hamerlik, P., Stockhausen, M. T., Ehrmann, J., Hlobilkova, A., Laursen, H., et al. (2010). Replication stress and oxidative damage contribute to aberrant constitutive activation of DNA damage signalling in human gliomas. Oncogene 29, 5095-5102. doi: 10.1038/onc.2010.249

Benayoun, B. A., and Veitia, R. A. (2009). A post-translational modification code for transcription factors: sorting through a sea of signals. Trends Cell Biol. 19, 189-197. doi: 10.1016/j.tcb.2009.02.003

Bergeron, R., Ren, J. M., Cadman, K. S., Moore, I. K., Perret, P., Pypaert, M., et al. (2001). Chronic activation of AMP kinase results in NRF-1 activation and mitochondrial biogenesis. Am. J. Physiol. Endocrinol. Metab. 281, E1340E1346.

Bettencourt-Dias, M., Giet, R., Sinka, R., Mazumdar, A., Lock, W. G., Balloux, F., et al. (2004). Genome-wide survey of protein kinases required for cell cycle progression. Nature 432, 980-987. doi: 10.1038/nature03160

Bhattacharyya, R. P., Remenyi, A., Yeh, B. J., and Lim, W. A. (2006). Domains, motifs, and scaffolds: the role of modular interactions in the evolution and wiring of cell signaling circuits. Annu. Rev. Biochem. 75, 655-680. doi: 10.1146/ annurev.biochem.75.103004.142710

Brugarolas, J. B., Vazquez, F., Reddy, A., Sellers, W. R., et al. (2003). TSC2 regulates VEGF through mTOR-dependent and -independent pathways. Cancer Cell 4, 147-158. doi: 10.1016/s1535-6108(03)00187-9

Brunet, A., Bonni, A., Zigmond, M. J., Lin, M. Z., Juo, P., Hu, L. S., et al. (1999). Akt promotes cell survival by phosphorylating and inhibiting a Forkhead transcription factor. Cell 96, 857-868. doi: 10.1016/s0092-8674(00)80595-4

Bungard, D., Fuerth, B. J., Zeng, P. Y., Faubert, B., Maas, N. L., Viollet, B., et al. (2010). Signaling kinase AMPK activates stress-promoted transcription via histone H2B phosphorylation. Science 329, 1201-1205. doi: 10.1126/science. 1191241

Canto, C., Gerhart-Hines, Z., Feige, J. N., Lagouge, M., Noriega, L., Milne, J. C., et al. (2009). AMPK regulates energy expenditure by modulating NAD+ metabolism and SIRT1 activity. Nature 458, 1056-1060. doi: 10.1038/ nature07813

Canto, C., Jiang, L. Q., Deshmukh, A. S., Mataki, C., Coste, A., Lagouge, M., et al. (2010). Interdependence of AMPK and SIRT1 for metabolic adaptation to

\section{AUTHOR CONTRIBUTIONS}

AS and $\mathrm{BD}$ wrote the manuscript. KC mined the ENCODE data. All authors contributed to the article and approved the submitted version.

\section{FUNDING}

This work was supported by National Institute of Health grants R01NS075291 and R01NS099162 to BD.

fasting and exercise in skeletal muscle. Cell Metab. 11, 213-219. doi: 10.1016/j. cmet.2010.02.006

Carling, D. (2017). AMPK signalling in health and disease. Curr. Opin. Cell Biol. 45, 31-37. doi: 10.1016/j.ceb.2017.01.005

Carling, D., and Hardie, D. G. (1989). The substrate and sequence specificity of the AMP-activated protein kinase. Phosphorylation of glycogen synthase and phosphorylase kinase. Biochim. Biophys. Acta 1012, 81-86. doi: 10.1016/01674889(89)90014- 1

Carling, D., Thornton, C., Woods, A., and Sanders, M. J. (2012). AMP-activated protein kinase: new regulation, new roles? Biochem. J. 445, 11-27. doi: 10.1042/ bj20120546

Carlson, M. (1999). Glucose repression in yeast. Curr. Opin. Microbiol. 2, 202-207. doi: 10.1016/s1369-5274(99)80035-6

Charest-Marcotte, A., Dufour, C. R., Wilson, B. J., Tremblay, A. M., Eichner, L. J., Arlow, D. H., et al. (2010). The homeobox protein Prox1 is a negative modulator of ERR $\alpha /$ PGC-1 $\alpha$ bioenergetic functions. Genes Dev. 24, 537-542. doi: $10.1101 / \operatorname{gad} .1871610$

Chen, K., and Rajewsky, N. (2007). The evolution of gene regulation by transcription factors and microRNAs. Nat. Rev. Genet. 8, 93-103. doi: 10.1038/ nrg1990

Chhipa, R. R., Fan, Q., Anderson, J., Muraleedharan, R., Huang, Y., Ciraolo, G., et al. (2018). AMP kinase promotes glioblastoma bioenergetics and tumour growth. Nat. Cell. Biol. 20, 823-835. doi: 10.1038/s41556-018-0126-z

Ciccone, D. N., Su, H., Hevi, S., Gay, F., Lei, H., Bajko, J., et al. (2009). KDM1B is a histone $\mathrm{H} 3 \mathrm{~K} 4$ demethylase required to establish maternal genomic imprints. Nature 461, 415-418. doi: 10.1038/nature08315

Collodet, C., Foretz, M., Deak, M., Bultot, L., Metairon, S., Viollet, B., et al. (2019). AMPK promotes induction of the tumor suppressor FLCN through activation of TFEB independently of mTOR. FASEB J. 33, 12374-12391. doi: 10.1096/fj. $201900841 \mathrm{r}$

Crute, B. E., Seefeld, K., Gamble, J., Kemp, B. E., and Witters, L. A. (1998). Functional domains of the alphal catalytic subunit of the AMP-activated protein kinase. J. Biol. Chem. 273, 35347-35354. doi: 10.1074/jbc.273.52.35347

Cunningham, J. T., Rodgers, J. T., Arlow, D. H., Vazquez, F., Mootha, V. K., and Puigserver, P. (2007). mTOR controls mitochondrial oxidative function through a YY1-PGC-1alpha transcriptional complex. Nature 450, 736-740. doi: $10.1038 /$ nature06322

Dasgupta, B., and Chhipa, R. R. (2016). Evolving lessons on the complex role of AMPK in normal physiology and cancer. Trends Pharmacol. Sci. 37, 192-206. doi: 10.1016/j.tips.2015.11.007

Dasgupta, B., Ju, J. S., Sasaki, Y., Liu, X., Jung, S. R., Higashida, K., et al. (2012). The AMPK beta2 subunit is required for energy homeostasis during metabolic stress. Mol. Cell Biol. 32, 2837-2848. doi: 10.1128/mcb.05853-11

Dasgupta, B., and Milbrandt, J. (2009). AMP-activated protein kinase phosphorylates retinoblastoma protein to control mammalian brain development. Dev. Cell 16, 256-270. doi: 10.1016/j.devcel.2009.01.005

Davies, S. P., Hawley, S. A., Woods, A., Carling, D., Haystead, T. A., and Hardie, D. G. (1994). Purification of the AMP-activated protein kinase on ATP-gammasepharose and analysis of its subunit structure. Eur. J. Biochem. 223, 351-357. doi: 10.1111/j.1432-1033.1994.tb19001.x

De Cesare, D., and Sassone-Corsi, P. (2000). Transcriptional regulation by cyclic AMP-responsive factors. Prog. Nucl. Acid Res. Mol. Biol. 64, 343-369. doi: 10.1016/s0079-6603(00)64009-6 
Dimitrova, E., Turberfield, A. H., and Klose, R. J. (2015). Histone demethylases in chromatin biology and beyond. Embo Rep. 16, 1620-1639. doi: 10.15252/embr. 201541113

Duvel, K., Yecies, J. L., Menon, S., Raman, P., Lipovsky, A. I., Souza, A. L., et al. (2010). Activation of a metabolic gene regulatory network downstream of mTOR complex 1. Mol. Cell 39, 171-183. doi: 10.1016/j.molcel.2010. 06.022

El-Houjeiri, L., Possik, E., Vijayaraghavan, T., Paquette, M., Martina, J. A., Kazan, J. M., et al. (2019). The transcription factors TFEB and TFE3 Link the FLCNAMPK signaling axis to innate immune response and pathogen resistance. Cell Rep. 26, 3613-3628.e3616.

Emanuelle, S., Hossain, M. I., Moller, I. E., Pedersen, H. L., Van De Meene, A. M., Doblin, M. S., et al. (2015). SnRK1 from Arabidopsis thaliana is an atypical AMPK. Plant J. 82, 183-192.

Etchegaray, J. P., and Mostoslavsky, R. (2016). Interplay between metabolism and epigenetics: a nuclear adaptation to environmental changes. Mol. Cell 62, 695-711. doi: 10.1016/j.molcel.2016.05.029

Etchegaray, J. P., Zhong, L., and Mostoslavsky, R. (2013). The histone deacetylase SIRT6: at the crossroads between epigenetics, metabolism and disease. Curr. Top. Med. Chem. 13, 2991-3000. doi: 10.2174/15680266113136660213

Filtz, T. M., Vogel, W. K., and Leid, M. (2014). Regulation of transcription factor activity by interconnected post-translational modifications. Trends Pharmacol. Sci. 35, 76-85. doi: 10.1016/j.tips.2013.11.005

Fisher, R. P., Lisowsky, T., Parisi, M. A., and Clayton, D. A. (1992). DNA wrapping and bending by a mitochondrial high mobility group-like transcriptional activator protein. J. Biol. Chem. 267, 3358-3367.

Fujiki, R., Hashiba, W., Sekine, H., Yokoyama, A., Chikanishi, T., Ito, S., et al. (2011). GlcNAcylation of histone H2B facilitates its monoubiquitination. Nature 480, 557-560. doi: 10.1038/nature10656

Fukuyama, Y., Ohta, K., Okoshi, R., Suehara, M., Kizaki, H., and Nakagawa, K. (2007). Hypoxia induces expression and activation of AMPK in rat dental pulp cells. J. Dent. Res. 86, 903-907. doi: 10.1177/154405910708600919

Garcia, D., and Shaw, R. J. (2017). AMPK: mechanisms of cellular energy sensing and restoration of metabolic balance. Mol Cell 66, 789-800. doi: 10.1016/j. molcel.2017.05.032

Garcia-Roves, P. M., Osler, M. E., Holmstrom, M. H., and Zierath, J. R. (2008). Gain-of-function R225Q mutation in AMP-activated protein kinase gamma3 subunit increases mitochondrial biogenesis in glycolytic skeletal muscle. J. Biol. Chem. 283, 35724-35734. doi: 10.1074/jbc.m805078200

Giannakou, M. E., Goss, M., Junger, M. A., Hafen, E., Leevers, S. J., and Partridge, L. (2004). Long-lived Drosophila with overexpressed dFOXO in adult fat body. Science 305:361. doi: 10.1126/science.1098219

Giguere, V. (2018). Canonical signaling and nuclear activity of mTOR-a teamwork effort to regulate metabolism and cell growth. FEBS J. 285, 1572-1588. doi: $10.1111 /$ febs.14384

Greer, E. L., Oskoui, P. R., Banko, M. R., Maniar, J. M., Gygi, M. P., Gygi, S. P., et al. (2007). The energy sensor AMP-activated protein kinase directly regulates the mammalian FOXO3 transcription factor. J. Biol. Chem. 282, 30107-30119. doi: $10.1074 /$ jbc.m705325200

Gwinn, D. M., Shackelford, D. B., Egan, D. F., Mihaylova, M. M., Mery, A., Vasquez, D. S., et al. (2008). AMPK phosphorylation of raptor mediates a metabolic checkpoint. Mol. Cell 30, 214-226. doi: 10.1016/j.molcel.2008.03.003

Han, H. S., Kang, G., Kim, J. S., Choi, B. H., and Koo, S. H. (2016). Regulation of glucose metabolism from a liver-centric perspective. Exp. Mol. Med. 48:e218. doi: $10.1038 /$ emm.2015.122

Handschin, C., and Spiegelman, B. M. (2006). Peroxisome proliferatoractivated receptor gamma coactivator 1 coactivators, energy homeostasis, and metabolism. Endocr. Rev. 27, 728-735. doi: 10.1210/er.2006-0037

Hardie, D. G. (2014a). AMP-activated protein kinase: maintaining energy homeostasis at the cellular and whole-body levels. Annu. Rev. Nutr. 34, 31-55. doi: 10.1146/annurev-nutr-071812-161148

Hardie, D. G. (2014b). AMPK-sensing energy while talking to other signaling pathways. Cell Metab. 20, 939-952. doi: 10.1016/j.cmet.2014.09.013

Hardie, D. G., Schaffer, B. E., and Brunet, A. (2016). AMPK: an energy-sensing pathway with multiple inputs and outputs. Trends Cell Biol. 26, 190-201. doi: 10.1016/j.tcb.2015.10.013

Hawley, S. A., Boudeau, J., Reid, J. L., Mustard, K. J., Udd, L., Makela, T. P., et al. (2003). Complexes between the LKB1 tumor suppressor, STRAD alpha/beta and MO25 alpha/beta are upstream kinases in the AMP-activated protein kinase cascade. J. Biol. 2:28.

Hawley, S. A., Pan, D. A., Mustard, K. J., Ross, L., Bain, J., Edelman, A. M., et al. (2005). Calmodulin-dependent protein kinase kinase-beta is an alternative upstream kinase for AMP-activated protein kinase. Cell Metab. 2, 9-19. doi: 10.1016/j.cmet.2005.05.009

Hedbacker, K., and Carlson, M. (2008). SNF1/AMPK pathways in yeast. Front. Biosci. 13:2408-2420. doi: 10.2741/2854

Herzig, S., and Shaw, R. J. (2018). AMPK: guardian of metabolism and mitochondrial homeostasis. Nat. Rev. Mol. Cell Biol. 19, 121-135. doi: 10.1038/ nrm.2017.95

Hindupur, S. K., Gonzalez, A., and Hall, M. N. (2015). The opposing actions of target of rapamycin and AMP-activated protein kinase in cell growth control. Cold Spring Harb. Perspect. Biol 7, a019141. doi: 10.1101/cshperspect.a019141

Holmes, B. F., Sparling, D. P., Olson, A. L., Winder, W. W., and Dohm, G. L. (2005). Regulation of muscle GLUT4 enhancer factor and myocyte enhancer factor 2 by AMP-activated protein kinase. Am. J. Physiol. Endocrinol. Metab. 289, E1071-E1076.

Hombach, D., Schwarz, J. M., Robinson, P. N., Schuelke, M., and Seelow, D. (2016). A systematic, large-scale comparison of transcription factor binding site models. BMC Genomics 17:388. doi: 10.1186/s12864-016-2729-8

Hong, S. P., Leiper, F. C., Woods, A., Carling, D., and Carlson, M. (2003). Activation of yeast Snfl and mammalian AMP-activated protein kinase by upstream kinases. Proc. Natl. Acad. Sci. U.S.A. 100, 8839-8843. doi: 10.1073/ pnas. 1533136100

Hudson, C. C., Liu, M., Chiang, G. G., Otterness, D. M., Loomis, D. C., Kaper, F., et al. (2002). Regulation of hypoxia-inducible factor lalpha expression and function by the mammalian target of rapamycin. Mol. Cell Biol. 22, 7004-7014. doi: $10.1128 / \mathrm{mcb} .22 .20 .7004-7014.2002$

Hurley, R. L., Anderson, K. A., Franzone, J. M., Kemp, B. E., Means, A. R., and Witters, L. A. (2005). The Ca2+/calmodulin-dependent protein kinase kinases are AMP-activated protein kinase kinases. J. Biol. Chem. 280, 29060-29066. doi: 10.1074/jbc.m503824200

Huss, J. M., Kopp, R. P., and Kelly, D. P. (2002). Peroxisome proliferator-activated receptor coactivator-1alpha (PGC-1alpha) coactivates the cardiac-enriched nuclear receptors estrogen-related receptor-alpha and -gamma. Identification of novel leucine-rich interaction motif within PGC-1alpha. J. Biol. Chem. 277, 40265-40274. doi: 10.1074/jbc.m206324200

Hwangbo, D. S., Gershman, B., Tu, M. P., Palmer, M., and Tatar, M. (2004). Drosophila dFOXO controls lifespan and regulates insulin signalling in brain and fat body. Nature 429, 562-566. doi: 10.1038/nature02549

Imai, S., and Guarente, L. (2014). NAD+ and sirtuins in aging and disease. Trends Cell Biol. 24, 464-471. doi: 10.1016/j.tcb.2014.04.002

Inoki, K., Zhu, T., and Guan, K. L. (2003). TSC2 mediates cellular energy response to control cell growth and survival. Cell 115, 577-590. doi: 10.1016/s00928674(03)00929-2

Irrcher, I., Ljubicic, V., Kirwan, A. F., and Hood, D. A. (2008). AMP-activated protein kinase-regulated activation of the PGC-1alpha promoter in skeletal muscle cells. PLoS One 3:e3614. doi: 10.1371/journal.pone.0003614

Jager, S., Handschin, C., St-Pierre, J., and Spiegelman, B. M. (2007). AMP-activated protein kinase (AMPK) action in skeletal muscle via direct phosphorylation of PGC-1alpha. Proc. Natl. Acad. Sci. U.S.A. 104, 12017-12022. doi: 10.1073/pnas. 0705070104

Jeremy, M., Berg, J. L. T., and And Lubert, S. (2002). Biochemistry. New York, NY: W.H. Freeman and Company.

Johnson, D. S., Mortazavi, A., Myers, R. M., and Wold, B. (2007). Genome-wide mapping of in vivo protein-DNA interactions. Science 316, 1497-1502.

Jorgensen, S. B., Wojtaszewski, J. F., Viollet, B., Andreelli, F., Birk, J. B., Hellsten, Y., et al. (2005). Effects of alpha-AMPK knockout on exercise-induced gene activation in mouse skeletal muscle. FASEB J. 19, 1146-1148. doi: 10.1096/fj. 04-3144fje

Kamei, Y., Ohizumi, H., Fujitani, Y., Nemoto, T., Tanaka, T., Takahashi, N., et al. (2003). PPARgamma coactivator lbeta/ERR ligand 1 is an ERR protein ligand, whose expression induces a high-energy expenditure and antagonizes obesity. Proc. Natl. Acad. Sci. U.S.A. 100, 12378-12383. doi: 10.1073/pnas.2135217100

Karacosta, L. G., Foster, B. A., Azabdaftari, G., Feliciano, D. M., and Edelman, A. M. (2012). A regulatory feedback loop between Ca2+/calmodulin-dependent protein kinase kinase 2 (CaMKK2) and the androgen receptor in prostate 
cancer progression. J. Biol. Chem. 287, 24832-24843. doi: 10.1074/jbc.m112. 370783

Karytinos, A., Forneris, F., Profumo, A., Ciossani, G., Battaglioli, E., Binda, C., et al. (2009). A novel mammalian flavin-dependent histone demethylase. J. Biol. Chem. 284, 17775-17782. doi: 10.1074/jbc.m109.003087

Katinka, M. D., Duprat, S., Cornillot, E., Metenier, G., Thomarat, F., Prensier, G., et al. (2001). Genome sequence and gene compaction of the eukaryote parasite Encephalitozoon cuniculi. Nature 414, 450-453. doi: 10.1038/35106579

Kawahara, T. L., Michishita, E., Adler, A. S., Damian, M., Berber, E., Lin, M., et al. (2009). SIRT6 links histone H3 lysine 9 deacetylation to NF-kappaBdependent gene expression and organismal life span. Cell 136, 62-74. doi: 10.1016/j.cell.2008.10.052

Kim, E., Goraksha-Hicks, P., Li, L., Neufeld, T. P., and Guan, K. L. (2008). Regulation of TORC1 by Rag GTPases in nutrient response. Nat. Cell Biol. 10, 935-945. doi: 10.1038/ncb1753

Kim, J. E., and Chen, J. (2004). regulation of peroxisome proliferator-activated receptor-gamma activity by mammalian target of rapamycin and amino acids in adipogenesis. Diabetes 53, 2748-2756. doi: 10.2337/diabetes.53.11.2748

Kim, J. H., Yoon, M. S., and Chen, J. (2009). Signal transducer and activator of transcription 3 (STAT3) mediates amino acid inhibition of insulin signaling through serine 727 phosphorylation. J. Biol. Chem. 284, 35425-35432. doi: $10.1074 /$ jbc.m109.051516

Kim, K., Pyo, S., and Um, S. H. (2012). S6 kinase 2 deficiency enhances ketone body production and increases peroxisome proliferator-activated receptor alpha activity in the liver. Hepatology 55, 1727-1737. doi: 10.1002/hep. 25537

Kishton, R. J., Barnes, C. E., Nichols, A. G., Cohen, S., Gerriets, V. A., Siska, P. J., et al. (2016). AMPK is essential to balance glycolysis and mitochondrial metabolism to control T-ALL cell stress and survival. Cell Metab. 23, 649-662. doi: 10.1016/j.cmet.2016.03.008

Klip, A., and Paquet, M. R. (1990). Glucose transport and glucose transporters in muscle and their metabolic regulation. Diabetes Care 13, 228-243. doi: 10.2337/diacare.13.3.228

Knight, J. B., Eyster, C. A., Griesel, B. A., and Olson, A. L. (2003). Regulation of the human GLUT4 gene promoter: interaction between a transcriptional activator and myocyte enhancer factor 2A. Proc. Natl. Acad. Sci. U.S.A. 100, 14725-14730. doi: 10.1073/pnas. 2432756100

Kodiha, M., Rassi, J. G., Brown, C. M., and Stochaj, U. (2007). Localization of AMP kinase is regulated by stress, cell density, and signaling through the MEK->ERK1/2 pathway. Am. J. Physiol. Cell Physiol. 293, C1427-C1436.

Koo, S. H., Flechner, L., Qi, L., Zhang, X., Screaton, R. A., Jeffries, S., et al. (2005). The CREB coactivator TORC2 is a key regulator of fasting glucose metabolism. Nature 437, 1109-1111.

Kops, G. J., De Ruiter, N. D., De Vries-Smits, A. M., Powell, D. R., Bos, J. L., and Burgering, B. M. (1999). Direct control of the Forkhead transcription factor AFX by protein kinase B. Nature 398, 630-634. doi: 10.1038/19328

Koyanagi, M., Asahara, S., Matsuda, T., Hashimoto, N., Shigeyama, Y., Shibutani, Y., et al. (2011). Ablation of TSC2 enhances insulin secretion by increasing the number of mitochondria through activation of mTORC1. PLoS One 6:e23238. doi: 10.1371/journal.pone.0023238

Kurth-Kraczek, E. J., Hirshman, M. F., Goodyear, L. J., and Winder, W. W. (1999). 5' AMP-activated protein kinase activation causes GLUT4 translocation in skeletal muscle. Diabetes 48, 1667-1671. doi: 10.2337/diabetes.48.8.1667

Laganiere, J., Tremblay, G. B., Dufour, C. R., Giroux, S., Rousseau, F., and Giguere, V. (2004). A polymorphic autoregulatory hormone response element in the human estrogen-related receptor alpha (ERRalpha) promoter dictates peroxisome proliferator-activated receptor gamma coactivator-1alpha control of ERRalpha expression. J. Biol. Chem. 279, 18504-18510. doi: 10.1074/jbc. m313543200

Laplante, M., and Sabatini, D. M. (2009). mTOR signaling at a glance. J. Cell Sci. 122, 3589-3594. doi: 10.1242/jcs.051011

Laplante, M., and Sabatini, D. M. (2012). mTOR signaling in growth control and disease. Cell 149, 274-293. doi: 10.1016/j.cell.2012.03.017

Laplante, M., and Sabatini, D. M. (2013). Regulation of mTORC1 and its impact on gene expression at a glance. J. Cell Sci. 126, 1713-1719. doi: 10.1242/jcs.125773

Laughner, E., Taghavi, P., Chiles, K., Mahon, P. C., and Semenza, G. L. (2001). HER2 (neu) signaling increases the rate of hypoxia-inducible factor 1alpha (HIF-1alpha) synthesis: novel mechanism for HIF-1-mediated vascular endothelial growth factor expression. Mol. Cell Biol. 21, 3995-4004. doi: 10. $1128 / \mathrm{mcb} .21 .12 .3995-4004.2001$
Lavin, M. F., and Gueven, N. (2006). The complexity of p53 stabilization and activation. Cell Death Differ. 13, 941-950. doi: 10.1038/sj.cdd.4401925

Le Lay, J., Tuteja, G., White, P., Dhir, R., Ahima, R., and Kaestner, K. H. (2009). CRTC2 (TORC2) contributes to the transcriptional response to fasting in the liver but is not required for the maintenance of glucose homeostasis. Cell Metab. 10, 55-62. doi: 10.1016/j.cmet.2009.06.006

Lee, J. H., Koh, H., Kim, M., Kim, Y., Lee, S. Y., Karess, R. E., et al. (2007). Energydependent regulation of cell structure by AMP-activated protein kinase. Nature $447,1017-1020$.

Leff, T. (2003). AMP-activated protein kinase regulates gene expression by direct phosphorylation of nuclear proteins. Biochem. Soc. Trans. 31, 224-227. doi: 10.1042/bst0310224

Lent, B., and Kim, K. H. (1982). Purification and properties of a kinase which phosphorylates and inactivates acetyl-CoA carboxylase. J. Biol. Chem. 257, 1897-1901.

Levy, E. D., Michnick, S. W., and Landry, C. R. (2012). Protein abundance is key to distinguish promiscuous from functional phosphorylation based on evolutionary information. Philos. Trans. R. Soc. Lond. B Biol. Sci. 367, 25942606. doi: 10.1098/rstb.2012.0078

Lewis, B. A., and Hanover, J. A. (2014). O-GlcNAc and the epigenetic regulation of gene expression. J. Biol. Chem. 289, 34440-34448. doi: 10.1074/jbc.r114.595439

Li, J. J., Bickel, P. J., and Biggin, M. D. (2014). System wide analyses have underestimated protein abundances and the importance of transcription in mammals. PeerJ 2:e270. doi: 10.7717/peerj.270

Li, S., Brown, M. S., and Goldstein, J. L. (2010). Bifurcation of insulin signaling pathway in rat liver: mTORC1 required for stimulation of lipogenesis, but not inhibition of gluconeogenesis. Proc. Natl. Acad. Sci. U.S.A. 107, 3441-3446. doi: 10.1073/pnas.0914798107

Li, S., Ogawa, W., Emi, A., Hayashi, K., Senga, Y., Nomura, K., et al. (2011). Role of S6K1 in regulation of SREBP1c expression in the liver. Biochem. Biophys. Res. Commun. 412, 197-202. doi: 10.1016/j.bbrc.2011.07.038

Li, T., Weng, J., Zhang, Y., Liang, K., Fu, G., Li, Y., et al. (2019). mTOR direct crosstalk with STAT5 promotes de novo lipid synthesis and induces hepatocellular carcinoma. Cell Death Dis. 10:619.

Lienhard, G. E. (2008). Non-functional phosphorylations? Trends Biochem. Sci. 33, 351-352. doi: 10.1016/j.tibs.2008.05.004

Lin, J., Wu, H., Tarr, P. T., Zhang, C. Y., Wu, Z., Boss, O., et al. (2002). Transcriptional co-activator PGC-1 alpha drives the formation of slow-twitch muscle fibres. Nature 418, 797-801. doi: 10.1038/nature00904

Lin, K., Dorman, J. B., Rodan, A., and Kenyon, C. (1997). daf-16: an HNF3/forkhead family member that can function to double the life-span of Caenorhabditis elegans. Science 278, 1319-1322. doi: 10.1126/science.278.5341. 1319

Lin, S. C., and Hardie, D. G. (2018). AMPK: sensing glucose as well as cellular energy status. Cell Metab. 27, 299-313. doi: 10.1016/j.cmet.2017.10.009

Liu, Y., Beyer, A., and Aebersold, R. (2016). On the dependency of cellular protein levels on mRNA abundance. Cell 165, 535-550. doi: 10.1016/j.cell.2016.03.014

Lo, W. S., Duggan, L., Emre, N. C., Belotserkovskya, R., Lane, W. S., Shiekhattar, R., et al. (2001). Snf1-a histone kinase that works in concert with the histone acetyltransferase Gcn5 to regulate transcription. Science 293, 1142-1146. doi: $10.1126 /$ science. 1062322

Loewith, R., and Hall, M. N. (2011). Target of rapamycin (TOR) in nutrient signaling and growth control. Genetics 189, 1177-1201. doi: 10.1534/genetics. 111.133363

Lu, J. Y., Lin, Y. Y., Sheu, J. C., Wu, J. T., Lee, F. J., Chen, Y., et al. (2011). Acetylation of yeast AMPK controls intrinsic aging independently of caloric restriction. Cell 146, 969-979. doi: 10.1016/j.cell.2011.07.044

Marsin, A. S., Bertrand, L., Rider, M. H., Deprez, J., Beauloye, C., Vincent, M. F., et al. (2000). Phosphorylation and activation of heart PFK-2 by AMPK has a role in the stimulation of glycolysis during ischaemia. Curr. Biol. 10, 1247-1255. doi: 10.1016/s0960-9822(00)00742-9

Martina, J. A., Chen, Y., Gucek, M., and Puertollano, R. (2012). MTORC1 functions as a transcriptional regulator of autophagy by preventing nuclear transport of TFEB. Autophagy 8, 903-914. doi: 10.4161/auto.19653

Mayer, C., Zhao, J., Yuan, X., and Grummt, I. (2004). mTOR-dependent activation of the transcription factor TIF-IA links rRNA synthesis to nutrient availability. Genes Dev. 18, 423-434. doi: 10.1101/gad.285504

McGee, S. L., Howlett, K. F., Starkie, R. L., Cameron-Smith, D., Kemp, B. E., and Hargreaves, M. (2003). Exercise increases nuclear AMPK alpha2 in 
human skeletal muscle. Diabetes 52, 926-928. doi: 10.2337/diabetes.52. 4.926

McGee, S. L., Sparling, D., Olson, A. L., and Hargreaves, M. (2006). Exercise increases MEF2- and GEF DNA-binding activity in human skeletal muscle. FASEB J. 20, 348-349. doi: 10.1096/fj.05-4671fje

McGee, S. L., Van Denderen, B. J., Howlett, K. F., Mollica, J., Schertzer, J. D., Kemp, B. E., et al. (2008). AMP-activated protein kinase regulates GLUT4 transcription by phosphorylating histone deacetylase 5. Diabetes 57, 860-867. doi: $10.2337 / \mathrm{db} 07-0843$

Medema, R. H., Kops, G. J., Bos, J. L., and Burgering, B. M. (2000). AFX-like Forkhead transcription factors mediate cell-cycle regulation by Ras and PKB through p27kip1. Nature 404, 782-787. doi: 10.1038/35008115

Mentch, S. J., Mehrmohamadi, M., Huang, L., Liu, X., Gupta, D., Mattocks, D., et al. (2015). Histone methylation dynamics and gene regulation occur through the sensing of one-carbon metabolism. Cell Metab. 22, 861-873. doi: 10.1016/j. cmet.2015.08.024

Michishita, E., Mccord, R. A., Berber, E., Kioi, M., Padilla-Nash, H., Damian, M., et al. (2008). SIRT6 is a histone H3 lysine 9 deacetylase that modulates telomeric chromatin. Nature 452, 492-496. doi: 10.1038/nature06736

Mihaylova, M. M., and Shaw, R. J. (2011). The AMPK signalling pathway coordinates cell growth, autophagy and metabolism. Nat. Cell Biol. 13, 10161023. doi: $10.1038 /$ ncb2329

Miranda-Saavedra, D., Stark, M. J., Packer, J. C., Vivares, C. P., Doerig, C., and Barton, G. J. (2007). The complement of protein kinases of the microsporidium Encephalitozoon cuniculi in relation to those of Saccharomyces cerevisiae and Schizosaccharomyces pombe. BMC Genomics 8:309. doi: 10.1186/1471-21648-309

Mirouse, V., Swick, L. L., Kazgan, N., St Johnston, D., and Brenman, J. E. (2007). LKB1 and AMPK maintain epithelial cell polarity under energetic stress. J. Cell Biol. 177, 387-392. doi: 10.1083/jcb.200702053

Mitchelhill, K. I., Stapleton, D., Gao, G., House, C., Michell, B., Katsis, F., et al. (1994). Mammalian AMP-activated protein kinase shares structural and functional homology with the catalytic domain of yeast Snf1 protein kinase. J. Biol. Chem. 269, 2361-2364.

Morgan, D. O. (1997). Cyclin-dependent kinases: engines, clocks, and microprocessors. Annu. Rev. Cell Dev. Biol. 13, 261-291. doi: 10.1146/annurev. cellbio.13.1.261

Nakae, J., Biggs, W. H. III, Kitamura, T., Cavenee, W. K., Wright, C. V., Arden, K. C., et al. (2002). Regulation of insulin action and pancreatic beta-cell function by mutated alleles of the gene encoding forkhead transcription factor Foxol. Nat. Genet. 32, 245-253. doi: 10.1038/ng890

Nakahata, Y., Sahar, S., Astarita, G., Kaluzova, M., and Sassone-Corsi, P. (2009). Circadian control of the NAD+ salvage pathway by CLOCK-SIRT1. Science 324, 654-657. doi: 10.1126/science.1170803

Nardini, M., Gnesutta, N., Donati, G., Gatta, R., Forni, C., Fossati, A., et al. (2013). Sequence-specific transcription factor NF-Y displays histone-like DNA binding and H2B-like ubiquitination. Cell 152, 132-143. doi: 10.1016/j.cell.2012.11.047

Nieborak, A., and Schneider, R. (2018). Metabolic intermediates - cellular messengers talking to chromatin modifiers. Mol. Metab. 14, 39-52. doi: 10. 1016/j.molmet.2018.01.007

Oakhill, J. S., Chen, Z. P., Scott, J. W., Steel, R., Castelli, L. A., Ling, N., et al. (2010). beta-Subunit myristoylation is the gatekeeper for initiating metabolic stress sensing by AMP-activated protein kinase (AMPK). Proc. Natl. Acad. Sci. U.S.A. 107, 19237-19241. doi: 10.1073/pnas.1009705107

Oakhill, J. S., Steel, R., Chen, Z. P., Scott, J. W., Ling, N., Tam, S., et al. (2011). AMPK is a direct adenylate charge-regulated protein kinase. Science 332, 1433-1435. doi: 10.1126/science.1200094

Ogg, S., Paradis, S., Gottlieb, S., Patterson, G. I., Lee, L., Tissenbaum, H. A., et al. (1997). The Fork head transcription factor DAF-16 transduces insulinlike metabolic and longevity signals in C. elegans. Nature 389, 994-999. doi: $10.1038 / 40194$

Orenstein, Y., and Shamir, R. (2014). A comparative analysis of transcription factor binding models learned from PBM, HT-SELEX and ChIP data. Nucleic Acids Res. 42, e63. doi: 10.1093/nar/gku117

Owen, J. L., Zhang, Y., Bae, S. H., Farooqi, M. S., Liang, G., Hammer, R. E., et al. (2012). Insulin stimulation of SREBP-1c processing in transgenic rat hepatocytes requires p70 S6-kinase. Proc. Natl. Acad. Sci. U.S.A. 109, 1618416189. doi: $10.1073 /$ pnas.1213343109
Paik, J. H., Kollipara, R., Chu, G., Ji, H., Xiao, Y., Ding, Z., et al. (2007). FoxOs are lineage-restricted redundant tumor suppressors and regulate endothelial cell homeostasis. Cell 128, 309-323. doi: 10.1016/j.cell.2006.12.029

Pastor, W. A., Aravind, L., and Rao, A. (2013). TETonic shift: biological roles of TET proteins in DNA demethylation and transcription. Nat. Rev. Mol. Cell Biol. 14, 341-356. doi: 10.1038/nrm3589

Polak, P., Cybulski, N., Feige, J. N., Auwerx, J., Ruegg, M. A., and Hall, M. N. (2008). Adipose-specific knockout of raptor results in lean mice with enhanced mitochondrial respiration. Cell Metab. 8, 399-410. doi: 10.1016/j.cmet.2008.09. 003

Polge, C., and Thomas, M. (2007). SNF1/AMPK/SnRK1 kinases, global regulators at the heart of energy control? Trends Plant Sci. 12, 20-28. doi: 10.1016/j. tplants.2006.11.005

Quentin, T., Kitz, J., Steinmetz, M., Poppe, A., Bar, K., and Kratzner, R. (2011). Different expression of the catalytic alpha subunits of the AMP activated protein kinase-an immunohistochemical study in human tissue. Histol. Histopathol. 26, 589-596.

Reznick, R. M., and Shulman, G. I. (2006). The role of AMP-activated protein kinase in mitochondrial biogenesis. J. Physiol. 574, 33-39. doi: 10.1113/jphysiol. 2006.109512

Rheinwald, J. G., and Green, H. (1974). Growth of cultured mammalian cells on secondary glucose sources. Cell 2, 287-293. doi: 10.1016/0092-8674(74)90 023-3

Rider, M. H. (2016). Role of AMP-activated protein kinase in metabolic depression in animals. J. Comp. Physiol. B 186, 1-16. doi: 10.1007/s00360-015-0920-x

Rios, M., Foretz, M., Viollet, B., Prieto, A., Fraga, M., Costoya, J. A., et al. (2013). AMPK activation by oncogenesis is required to maintain cancer cell proliferation in astrocytic tumors. Cancer Res. 73, 2628-2638. doi: 10.1158/ 0008-5472.can-12-0861

Roczniak-Ferguson, A., Petit, C. S., Froehlich, F., Qian, S., Ky, J., Angarola, B., et al. (2012). The transcription factor TFEB links mTORC1 signaling to transcriptional control of lysosome homeostasis. Sci. Signal. 5:ra42. doi: 10. 1126/scisignal.2002790

Rogatzki, M. J., Ferguson, B. S., Goodwin, M. L., and Gladden, L. B. (2015). Lactate is always the end product of glycolysis. Front. Neurosci. 9:22. doi: 10.3389/fnins. 2015.00022

Rorsman, P., and Braun, M. (2013). Regulation of insulin secretion in human pancreatic islets. Annu. Rev. Physiol. 75, 155-179. doi: 10.1146/annurevphysiol-030212-183754

Rui, L. (2014). Energy metabolism in the liver. Compr. Physiol. 4, 177-197. doi: $10.1002 /$ cphy.c130024

Sakabe, K., Wang, Z., and Hart, G. W. (2010). Beta-N-acetylglucosamine (OGlcNAc) is part of the histone code. Proc. Natl. Acad. Sci. U.S.A. 107, 1991519920. doi: 10.1073/pnas.1009023107

Salt, I. P., Johnson, G., Ashcroft, S. J., and Hardie, D. G. (1998). AMP-activated protein kinase is activated by low glucose in cell lines derived from pancreatic beta cells, and may regulate insulin release. Biochem. J. 335(Pt 3), 533-539. doi: 10.1042/bj3350533

Saltiel, A. R., and Kahn, C. R. (2001). Insulin signalling and the regulation of glucose and lipid metabolism. Nature 414, 799-806. doi: 10.1038/414799a

Sancak, Y., Peterson, T. R., Shaul, Y. D., Lindquist, R. A., Thoreen, C. C., Bar-Peled, L., et al. (2008). The Rag GTPases bind raptor and mediate amino acid signaling to mTORC1. Science 320, 1496-1501. doi: 10.1126/science.1157535

Saxton, R. A., and Sabatini, D. M. (2017). mTOR signaling in growth, metabolism, and disease. Cell 168, 960-976. doi: 10.1016/j.cell.2017.02.004

Scarpulla, R. C. (2006). Nuclear control of respiratory gene expression in mammalian cells. J. Cell Biochem. 97, 673-683. doi: 10.1002/jcb.20743

Schreiber, S. N., Knutti, D., Brogli, K., Uhlmann, T., and Kralli, A. (2003). The transcriptional coactivator PGC-1 regulates the expression and activity of the orphan nuclear receptor estrogen-related receptor alpha (ERRalpha). J. Biol. Chem. 278, 9013-9018. doi: 10.1074/jbc.m212923200

Schuit, F. C., In't Veld, P. A., and Pipeleers, D. G. (1988). Glucose stimulates proinsulin biosynthesis by a dose-dependent recruitment of pancreatic beta cells. Proc. Natl. Acad. Sci. U.S.A. 85, 3865-3869. doi: 10.1073/pnas.85.11. 3865

Scott, J. D., and Pawson, T. (2009). Cell signaling in space and time: where proteins come together and when they're apart. Science 326, 1220-1224. doi: 10.1126/ science. 1175668 
Sengupta, S., Peterson, T. R., Laplante, M., Oh, S., and Sabatini, D. M. (2010). mTORC1 controls fasting-induced ketogenesis and its modulation by ageing. Nature 468, 1100-1104. doi: 10.1038/nature09584

Settembre, C., Zoncu, R., Medina, D. L., Vetrini, F., Erdin, S., Erdin, S., et al. (2012). A lysosome-to-nucleus signalling mechanism senses and regulates the lysosome via mTOR and TFEB. Embo J. 31, 1095-1108. doi: 10.1038/emboj.2012.32

Shaw, R. J., Kosmatka, M., Bardeesy, N., Hurley, R. L., Witters, L. A., Depinho, R. A., et al. (2004). The tumor suppressor LKB1 kinase directly activates AMPactivated kinase and regulates apoptosis in response to energy stress. Proc. Natl. Acad. Sci. U.S.A. 101, 3329-3335. doi: 10.1073/pnas.0308061100

Shen, W., Reyes, M. I., and Hanley-Bowdoin, L. (2009). Arabidopsis protein kinases GRIK1 and GRIK2 specifically activate SnRK1 by phosphorylating its activation loop. Plant Physiol. 150, 996-1005. doi: 10.1104/pp.108.132787

Shi, Y., Lan, F., Matson, C., Mulligan, P., Whetstine, J. R., Cole, P. A., et al. (2004). Histone demethylation mediated by the nuclear amine oxidase homolog LSD1. Cell 119, 941-953.

Shi, Y., and Whetstine, J. R. (2007). Dynamic regulation of histone lysine methylation by demethylases. Mol. Cell 25, 1-14. doi: 10.1016/j.molcel.2006. 12.010

Siques, P., Brito, J., Flores, K., Ordenes, S., Arriaza, K., Pena, E., et al. (2018). Long-term chronic intermittent hypobaric hypoxia induces glucose transporter (GLUT4) translocation through AMP-Activated Protein Kinase (AMPK) in the soleus muscle in lean rats. Front. Physiol. 9:799. doi: 10.3389/fphys.2018.00799

Smith, F. C., Davies, S. P., Wilson, W. A., Carling, D., and Hardie, D. G. (1999). The SNF1 kinase complex from Saccharomyces cerevisiae phosphorylates the transcriptional repressor protein Miglp in vitro at four sites within or near regulatory domain 1. FEBS Lett. 453, 219-223. doi: 10.1016/s0014-5793(99) 00725-5

Sonoda, J., Laganiere, J., Mehl, I. R., Barish, G. D., Chong, L. W., Li, X., et al. (2007). Nuclear receptor ERR alpha and coactivator PGC-1 beta are effectors of IFN-gamma-induced host defense. Genes Dev. 21, 1909-1920. doi: 10.1101/ gad. 1553007

Spasic, M. R., Callaerts, P., and Norga, K. K. (2008). Drosophila alicorn is a neuronal maintenance factor protecting against activity-induced retinal degeneration. J. Neurosci. 28, 6419-6429. doi: 10.1523/jneurosci.1646-08.2008

Stenesen, D., Suh, J. M., Seo, J., Yu, K., Lee, K. S., Kim, J. S., et al. (2013). Adenosine nucleotide biosynthesis and AMPK regulate adult life span and mediate the longevity benefit of caloric restriction in flies. Cell Metab. 17, 101-112. doi: 10.1016/j.cmet.2012.12.006

Suwa, M., Nakano, H., and Kumagai, S. (2003). Effects of chronic AICAR treatment on fiber composition, enzyme activity, UCP3, and PGC-1 in rat muscles. J. Appl. Physiol. 95, 960-968. doi: 10.1152/japplphysiol.00349.2003

Sweet, S., and Singh, G. (1995). Accumulation of human promyelocytic leukemic (HL-60) cells at two energetic cell cycle checkpoints. Cancer Res. 55, 5164-5167.

Takusagawa, F., Kamitori, S., and Markham, G. D. (1996). Structure and function of S-adenosylmethionine synthetase: crystal structures of S-adenosylmethionine synthetase with ADP, BrADP, and PPi at 28 angstroms resolution. Biochemistry 35, 2586-2596. doi: 10.1021/bi952604z

Tang, T. T., Dowbenko, D., Jackson, A., Toney, L., Lewin, D. A., Dent, A. L., et al. (2002). The forkhead transcription factor AFX activates apoptosis by induction of the BCL-6 transcriptional repressor. J. Biol. Chem. 277, 14255-14265. doi: 10.1074/jbc.m110901200

Terada, S., Goto, M., Kato, M., Kawanaka, K., Shimokawa, T., and Tabata, I. (2002). Effects of low-intensity prolonged exercise on PGC-1 mRNA expression in rat epitrochlearis muscle. Biochem. Biophys. Res. Commun. 296, 350-354. doi: 10.1016/s0006-291x(02)00881-1

Thaiparambil, J. T., Eggers, C. M., and Marcus, A. I. (2012). AMPK regulates mitotic spindle orientation through phosphorylation of myosin regulatory light chain. Mol. Cell Biol. 32, 3203-3217. doi: 10.1128/mcb.00418-12

Thomson, D. M., Hancock, C. R., Evanson, B. G., Kenney, S. G., Malan, B. B., Mongillo, A. D., et al. (2010). Skeletal muscle dysfunction in musclespecific LKB1 knockout mice. J. Appl. Physiol. 108, 1775-1785. doi: 10.1152/ japplphysiol.01293.2009

Treitel, M. A., Kuchin, S., and Carlson, M. (1998). Snf1 protein kinase regulates phosphorylation of the Mig1 repressor in Saccharomyces cerevisiae. Mol. Cell Biol. 18, 6273-6280. doi: 10.1128/mcb.18.11.6273

Tsang, C. K., Liu, H., and Zheng, X. F. (2010). mTOR binds to the promoters of RNA polymerase I- and III-transcribed genes. Cell Cycle 9, 953-957. doi: $10.4161 /$ cc. 9.5 .10876 van Dam, T. J., Zwartkruis, F. J., Bos, J. L., and Snel, B. (2011). Evolution of the TOR pathway. J. Mol. Evol. 73, 209-220.

van der Knaap, J. A., and Verrijzer, C. P. (2016). Undercover: gene control by metabolites and metabolic enzymes. Genes Dev. 30, 2345-2369. doi: 10.1101/ gad.289140.116

Vaquero, A., Scher, M. B., Lee, D. H., Sutton, A., Cheng, H. L., Alt, F. W., et al. (2006). SirT2 is a histone deacetylase with preference for histone H4 Lys 16 during mitosis. Genes Dev. 20, 1256-1261. doi: 10.1101/gad.1412706

Vara-Ciruelos, D., Dandapani, M., Gray, A., Egbani, E. O., Evans, A. M., and Hardie, D. G. (2018). Genotoxic damage activates the AMPK-alphal isoform in the nucleus via $\mathrm{Ca}(2+) / \mathrm{CaMKK} 2$ signaling to enhance tumor cell survival. Mol. Cancer Res. 16, 345-357. doi: 10.1158/1541-7786.mcr-170323

Vazquez-Martin, A., Oliveras-Ferraros, C., and Menendez, J. A. (2009). The active form of the metabolic sensor: AMP-activated protein kinase (AMPK) directly binds the mitotic apparatus and travels from centrosomes to the spindle midzone during mitosis and cytokinesis. Cell Cycle 8, 2385-2398. doi: 10.4161/ cc.8.15.9082

Vincent, O., Townley, R., Kuchin, S., and Carlson, M. (2001). Subcellular localization of the Snfl kinase is regulated by specific beta subunits and a novel glucose signaling mechanism. Genes Dev. 15, 1104-1114. doi: 10.1101/gad. 879301

Viollet, B., Andreelli, F., Jorgensen, S. B., Perrin, C., Flamez, D., Mu, J., et al. (2003a). Physiological role of AMP-activated protein kinase (AMPK): insights from knockout mouse models. Biochem. Soc. Trans. 31, 216-219. doi: 10.1042/ bst0310216

Viollet, B., Andreelli, F., Jorgensen, S. B., Perrin, C., Geloen, A., Flamez, D., et al. (2003b). The AMP-activated protein kinase alpha2 catalytic subunit controls whole-body insulin sensitivity. J. Clin. Invest. 111, 91-98. doi: 10.1172/jci 16567

Viollet, B., Horman, S., Leclerc, J., Lantier, L., Foretz, M., Billaud, M., et al. (2010). AMPK inhibition in health and disease. Crit. Rev. Biochem. Mol. Biol. 45, 276-295.

Virbasius, J. V., and Scarpulla, R. C. (1994). Activation of the human mitochondrial transcription factor A gene by nuclear respiratory factors: a potential regulatory link between nuclear and mitochondrial gene expression in organelle biogenesis. Proc. Natl. Acad. Sci. U.S.A. 91, 1309-1313. doi: 10.1073/pnas.91.4. 1309

Vogel, C., and Marcotte, E. M. (2012). Insights into the regulation of protein abundance from proteomic and transcriptomic analyses. Nat. Rev. Genet. 13, 227-232. doi: 10.1038/nrg3185

Wang, B. T., Ducker, G. S., Barczak, A. J., Barbeau, R., Erle, D. J., and Shokat, K. M. (2011). The mammalian target of rapamycin regulates cholesterol biosynthetic gene expression and exhibits a rapamycin-resistant transcriptional profile. Proc. Natl. Acad. Sci. U.S.A. 108, 15201-15206. doi: 10.1073/pnas.1103746108

Wang, M., and Kaufman, R. J. (2014). The impact of the endoplasmic reticulum protein-folding environment on cancer development. Nat. Rev. Cancer 14, 581-597. doi: 10.1038/nrc3800

Wang, Y., Guo, Y. R., Liu, K., Yin, Z., Liu, R., Xia, Y., et al. (2017). KAT2A coupled with the alpha-KGDH complex acts as a histone H3 succinyltransferase. Nature 552, 273-277. doi: 10.1038/nature25003

Wei, Y., Tsang, C. K., and Zheng, X. F. (2009). Mechanisms of regulation of RNA polymerase III-dependent transcription by TORC1. EMBO J. 28, 2220-2230. doi: 10.1038/emboj.2009.179

Woods, A., Dickerson, K., Heath, R., Hong, S. P., Momcilovic, M., Johnstone, S. R., et al. (2005). Ca2+/calmodulin-dependent protein kinase kinase-beta acts upstream of AMP-activated protein kinase in mammalian cells. Cell Metab. 2, 21-33. doi: 10.1016/j.cmet.2005.06.005

Wu, R., Haas, W., Dephoure, N., Huttlin, E. L., Zhai, B., Sowa, M. E., et al. (2011). A large-scale method to measure absolute protein phosphorylation stoichiometries. Nat. Methods 8, 677-683. doi: 10.1038/nmeth.1636

Xi, X., Han, J., and Zhang, J. Z. (2001). Stimulation of glucose transport by AMPactivated protein kinase via activation of p38 mitogen-activated protein kinase. J. Biol. Chem. 276, 41029-41034. doi: 10.1074/jbc.m102824200

Xiao, B., Sanders, M. J., Underwood, E., Heath, R., Mayer, F. V., Carmena, D., et al. (2011). Structure of mammalian AMPK and its regulation by ADP. Nature 472, 230-233. doi: 10.1038/nature09932

Xiao, M., Yang, H., Xu, W., Ma, S., Lin, H., Zhu, H., et al. (2012). Inhibition of alpha-KG-dependent histone and DNA demethylases by fumarate and 
succinate that are accumulated in mutations of $\mathrm{FH}$ and SDH tumor suppressors. Genes Dev. 26, 1326-1338. doi: 10.1101/gad.191056.112

Yang, W., Hong, Y. H., Shen, X. Q., Frankowski, C., Camp, H. S., and Leff, T. (2001). Regulation of transcription by AMP-activated protein kinase: phosphorylation of p300 blocks its interaction with nuclear receptors. J. Biol. Chem. 276, 38341-38344. doi: 10.1074/jbc.c100316200

Yecies, J. L., Zhang, H. H., Menon, S., Liu, S., Yecies, D., Lipovsky, A. I., et al. (2011). Akt stimulates hepatic SREBP1c and lipogenesis through parallel mTORC1dependent and independent pathways. Cell Metab. 14, 21-32. doi: 10.1016/j. cmet.2011.06.002

Yokogami, K., Wakisaka, S., Avruch, J., and Reeves, S. A. (2000). Serine phosphorylation and maximal activation of STAT3 during CNTF signaling is mediated by the rapamycin target mTOR. Curr. Biol. 10, 47-50. doi: 10.1016/ s0960-9822(99)00268-7

Young, M. E., Radda, G. K., and Leighton, B. (1996). Activation of glycogen phosphorylase and glycogenolysis in rat skeletal muscle by AICAR-an activator of AMP-activated protein kinase. FEBS Lett. 382, 43-47. doi: 10.1016/00145793(96)00129-9

Young, N. P., Kamireddy, A., Van Nostrand, J. L., Eichner, L. J., Shokhirev, M. N., Dayn, Y., et al. (2016). AMPK governs lineage specification through Tfebdependent regulation of lysosomes. Genes Dev. 30, 535-552. doi: 10.1101/gad. 274142.115
Zhang, C. S., Jiang, B., Li, M., Zhu, M., Peng, Y., Zhang, Y. L., et al. (2014). The lysosomal v-ATPase-Ragulator complex is a common activator for AMPK and mTORC1, acting as a switch between catabolism and anabolism. Cell Metab. 20, 526-540. doi: 10.1016/j.cmet.2014.06.014

Zhang, Y. L., Guo, H., Zhang, C. S., Lin, S. Y., Yin, Z., Peng, Y., et al. (2013). AMP as a low-energy charge signal autonomously initiates assembly of AXINAMPK-LKB1 complex for AMPK activation. Cell Metab. 18, 546-555. doi: 10.1016/j.cmet.2013.09.005

Zhong, L., D’urso, A., Toiber, D., Sebastian, C., Henry, R. E., Vadysirisack, D. D., et al. (2010). The histone deacetylase Sirt6 regulates glucose homeostasis via Hif1alpha. Cell 140, 280-293. doi: 10.1016/j.cell.2009.12.041

Conflict of Interest: The authors declare that the research was conducted in the absence of any commercial or financial relationships that could be construed as a potential conflict of interest.

Copyright (C) 2020 Sukumaran, Choi and Dasgupta. This is an open-access article distributed under the terms of the Creative Commons Attribution License (CC BY).

The use, distribution or reproduction in other forums is permitted, provided the original author(s) and the copyright owner(s) are credited and that the original publication in this journal is cited, in accordance with accepted academic practice. No use, distribution or reproduction is permitted which does not comply with these terms. 